\title{
PADRÃO DA PAISAGEM ASSOCIADO AO USO E COBERTURA DA TERRA EM COMUNIDADES RIBEIRINHAS E DE TERRA FIRME SITUADAS NO SUDOESTE DO PARÁ
}

\author{
Anielli Rosane de SOUZA \\ Maria Isabel Sobral ESCADA \\ Antônio Miguel Vieira MONTEIRO3
}

\section{Resumo}

O presente artigo faz uma análise de padrões de paisagem associados ao uso e cobertura da terra de áreas no entorno de comunidades ribeirinhas e de terra firme da região sudoeste do Pará, com indicadores na escala da paisagem que medem a intensificação do uso da terra e a diversidade da paisagem. Esses indicadores foram utilizados conjuntamente com dados obtidos em levantamentos de campo, relativos à produção agropecuária e extrativista, possibilitando caracterizar o padrão da paisagem e o potencial econômico associado às atividades de uso e cobertura da terra, além de inferir por meio da análise de padrões da paisagem e de dados da produção, a possibilidade de inserção das comunidades em Arranjos Produtivos Locais, em cadeias econômicas constituídas ou a se constituir. Para a geração desses indicadores foram considerados modelos teóricos sobre intensificação, o uso de métrica de diversidade da paisagem, além de dados de uso e cobertura da terra do TerraClass-2012, contidos no espaço celular de $[8 \times 8] \mathrm{km}$, integrados a partir de técnicas de geoprocessamento. Os indicadores apontaram que a intensificação na região está em curso e a paisagem não foi totalmente incorporada pelo agronegócio, nem dominada por uma única classe de cobertura da terra. Embora, as áreas de agricultura anual (agronegócio) nas proximidades de Santarém, Belterra e Mojuí dos Campos, sejam mais intensificadas do que as de áreas de agricultura familiar, observou-se que elas também têm os maiores índices de diversidade. Essa aparente contradição se dá porque a região ainda compartilha o espaço, onde se estabeleceu a produção de grãos, com a agricultura familiar e a pecuária. Porém, com o avanço do agronegócio na região, a partir da implantação de novos projetos e logísticas de transporte a tendência é de que novas áreas sejam incorporadas, implicando em uma significativa redução da diversidade da paisagem, especialmente se considerarmos o Estado do Mato Grosso como referência, onde há alta concentração de terras e grande pressão sobre as terras dos pequenos produtores rurais. Essa redução implica na diminuição de alternativas econômicas e de subsistência para a população local inserida nessas regiões, resultando em uma paisagem com baixo potencial econômico, seja para geração de renda, ou para criação de condições para subsistência.

Palavras-chave: Uso e cobertura da terra. Intensificação. Índice de Diversidade de Shannon. Análise da paisagem. Amazônia.

\footnotetext{
${ }^{1}$ Mestranda em Sensoriamento Remoto/ Instituto Nacional de Pesquisas Espaciais - INPE. Endereço: Av. dos Astronautas, 1758, Jd. da Granja, CEP: 12227-010 São José dos Campos, SP. E-mail: anielli@dpi.inpe.br

2 Pesquisadora/Instituto Nacional de Pesquisas Espaciais - INPE. Endereço: Av. dos Astronautas, 1758, Jd. da Granja, CEP: 12227-010 - São José dos Campos, SP. E-mail: isabel@dpi.inpe.br

3 Pesquisador/Instituto Nacional de Pesquisas Espaciais - INPE. Endereço: Av. dos Astronautas, 1758, Jd. da Granja, CEP: 12227-010 - São José dos Campos, SP. E-mail: miguel@dpi.inpe.br
} 


\section{Abstract}

\section{Landscape Patterns associated to use and land cover in riverine and "terra firme" communities in Southwest of Pará}

This paper presents an analysis of landscape patterns associated to land use and land cover activities around riverine and "Terra Firme" communities, in the Southwestern region of Pará based on indicators at landscape scale which measure land use intensification and landscape diversity. These indicators were used in the analysis coupled with the data obtained from field work surveys related to agricultural and extractive production. The analysis allowed us to characterize the landscape pattern and the economic potential associated with land use activities as well as to infer about the different patterns of landscape and production providing a discussion about the possibility of including communities in productive arrangements of existing economic networks or new ones. For the development of these indicators we considered intensification theoretical models, landscape diversity metrics, and land cover and land use data from TerraClass-2012 in a cellular database $[8 \times 8] \mathrm{km}$, integrated from GIS techniques. The indicators showed that intensification in the region is still ongoing and that the landscape has not been fully incorporated by agribusiness pattern, nor a single land use class has dominate it yet. Although the areas of annual agriculture (agribusiness) near Santarém, Belterra and Mojuí dos Campos are more intensified than the areas of small household farming, they also have the highest value of diversity in the study area. This apparent contradiction is because the region still shares the space with other activities, grain production, small household farming and cattle raising. However, with the advance of agribusiness in the region and the establishment of new projects and logistics of transport the trend is that new areas might be added to agribusiness land, resulting in a significant reduction of the landscape diversity especially considering Mato Grosso state as reference, where there is a high concentration of land and a strong pressure on small household lands, resulting in a significant reduction in the landscape diversity. This reduction would imply in the decrease of economic alternatives and livelihood for the local population inserted in these regions, resulting in a landscape with low economic potential to generate income or living conditions.

Key words: Land use, Land cover. Intensification. Shannon Diversity Index. Landscape analysis. Amazonia.

\section{INTRODUÇÃO}

A Amazônia é marcada por diferentes processos e históricos de ocupação, iniciados nas faixas ribeirinhas antes da década de 60 e, depois, nas áreas de terra firme, ao longo das rodovias federais, e nos projetos de colonização públicos ou privados. Os diferentes tipos de ocupação, bem como a migração induzida pelo governo, contribuíram fortemente para a expansão da fronteira agrícola na Amazônia a partir dos anos 70 (BECKER,1995, 1990; MACHADO, 1998;). Nessas áreas, diferentes atividades econômicas ligadas ao uso e cobertura da terra se sucederam. Anterior a 1960, as atividades econômicas na região ribeirinha eram voltadas principalmente para as atividades extrativistas, como a coleta de produtos florestais, a pesca e a extração da borracha, algumas vezes, conjugadas com a agricultura de subsistência. Posterior à década de 1960, nas áreas de terra firme, as atividades agropastoris passaram a predominar, sobrepondo-se às atividades extrativistas desenvolvidas nas margens dos rios (BECKER et. al. 1990; BROWDER; GODFREY,1997; COSTA, 2012a). Mais recentemente, no final dos anos 90, observa-se a introdução da agricultura de larga escala voltada para a produção de grãos, principalmente de soja, nos Estados do Mato Grosso, Rondônia e do Pará. No Sudoeste do Pará essa atividade concentrou- 
se nos municípios de Santarém, Mojuí dos Campos e Belterra (D'ANTONA et al., 2011; DAL'ASTA et. al, 2013; WALKER et al, 2013).

De uma forma geral, com a entrada de sistemas de produção mais intensivos, como os dos grandes pecuaristas e do agronegócio, a produção familiar passa a ter maiores dificuldades para se inserir em razão dos diferenciais em produtividade, estabelecidos nos sistemas de produção, na tecnologia, tecnificação e mão de obra, e no acesso a mercados, dependentes de regulação, crédito e organização para o estabelecimento de arranjos produtivos locais (APL) (AMARAL FILHO, 2011; MATOS, BORIN; CASSIOLATO, 2015). Nesse cenário de intensificação, os pequenos produtores passam a conviver com uma situação desfavorável, disputando o mercado local e regional com uma produção de menor custo e maior lucratividade (BRONDIZIO et al, 2013 WALKER et al, 2013; HOMMA et al, 2014). Ainda mais grave, a intensificação, como conduzida, pode levar à criação de uma nova estruturação do espaço regional, que se impõe com novas lógicas territoriais, a partir de processos de concentração de terra, excluindo, com frequência, os pequenos produtores locais (BRONDÍZIO; SIQUEIRA, 1997; BOSERUP, 1970; MONTE-MÓR,2008). Esse processo foi observado por Coy (1987), Pedlowsky e Dale (1992), Escada (2003) e Silva et al (2008) em Rondônia; Mertens et al (2002) no sudeste do Pará e; D'Antona et al (2011) e Dal'Asta et al., (2013) em Santarém. Essa nova lógica de organização do território modifica a paisagem $^{4}$, e essas mudanças deixam marcas que são expressas em padrões espaciais que variam de acordo com os atores presentes e suas formas de produção (ALVES et al, 2013). Os processos de concentração de terras tendem a excluir grupos sociais que guardam parte do conhecimento sobre a biodiversidade local, reduzindo-se as chances de incorporar alternativas econômicas que se baseiam nos saberes e práticas locais que, quando combinados com o uso de novas tecnologias e a promoção de cadeias econômicas estruturadas em torno de APLs (COSTA, INHETVIN, 2006; COSTA, 2010; OLIVEIRA; SANTANA, 2012; FRANCA, 2013), podem ser de grande importância na promoção de um desenvolvimento regional inclusivo, diversificado, e ambientalmente sustentado.

O conceito de intensificação do uso terra utilizado nesse trabalho relaciona-se com a eficiência produtiva do sistema agropecuário, na qual se objetiva elevar ao máximo a produção de uma área com custos mais baixos, a fim de aumentar a produtividade e, consequentemente, o lucro (HOMMA, 2012). A intensificação decorre da combinação de diferentes fatores, tais como, o aumento no investimento de capital e de estrutura física, a incorporação de modernização tecnológica, a substituição da mão de obra humana por mecanização e equipamentos mais automatizados, e na região amazônica, o aumento da concentração das terras (BOSERUP, 1970; BRONDÍZIO, 2006; COSTA, 2009; HOMMA, 2012).

Em decorrência da intensificação, dois efeitos podem ser observados na paisagem: 1) a dominância de um determinado tipo de cobertura, em decorrência do uso de grandes extensões de área e de processos de concentração de terra, implicando na produção de paisagens com baixa diversidade de usos e coberturas da terra (COY,1987; PEDLOWSKY; DALE, 1992; ESCADA, 2003; SILVA et al., 2008; MERTENS et al, 2002; D'ANTONA et al., 2011) e; 2) a redução da área de produção e,

\footnotetext{
4 "Em diferentes línguas, paisagem significa diferentes coisas, mas o denominador comum é a demarcação territorial. Demarcação permite que a noção de paisagem possa funcionar como um arcabouço para outras perspectivas como a da estética, da política, da agricultura, do turismo, da espiritualidade, da geologia, da cultura, da ecologia, da hidrologia, da tecnologia, da tradição, da educação, da militar, etc. A vantagem do conceito da paisagem desta forma é que ele tem poder para se mover em direção a uma compreensão mais complexa das interações entre os diferentes fatores humanos e naturais em uma demarcação territorial limitada. Paisagem não é uma imagem estática, mas sim uma expressão de forças históricas e naturais que moldam o ambiente". (BIGELL; CHANG, 2014, p. 101).
} 
consequentemente, a liberação de outras áreas para diferentes usos, diversificando a produção e produzindo uma paisagem com maior diversidade de usos e coberturas (BRONDÍZIO; SIQUEIRA, 1997; HOMMA, 2012).

O termo diversidade da paisagem, adotado neste trabalho, se refere ao conceito da ecologia, no qual a diversidade está relacionada com a abundância (proporção) e a riqueza (número) de espécies presentes na paisagem (MCGARIGAL; MARKS, 1995; METZGER, 2001). Neste estudo, ao invés de espécies, são analisadas as classes de uso e cobertura da terra. Desta forma, a diversidade é obtida a partir de um índice que relaciona abundância e riqueza de classes de uso e cobertura da terra, como uma medida de composição e de diversidade da paisagem (MCGARIGAL; MARKS, 1995).

Indicadores de diversidade da paisagem são utilizados nesse trabalho para avaliar paisagens com maior ou menor potencial de desenvolvimento econômico associado ao uso da terra. Supomos que todas as coberturas da terra avaliadas têm a possibilidade de serem utilizadas economicamente.

Paisagens pouco diversificadas oferecem um potencial econômico reduzido para as populações que não estão envolvidas diretamente no sistema de produção agropecuário dominante, com poucas alternativas de geração de renda associadas às atividades de uso da terra. Comunidades inseridas em diferentes contextos de intensificação do uso da terra podem apresentar ao seu redor, maior ou menor diversidade de uso e cobertura da terra, apresentando, assim, diferentes alternativas e potenciais para inserção em circuitos econômicos. Além das atividades agropecuárias, a presença de recursos naturais, como rios e floresta, possibilita que atividades extrativistas como a pesca e a coleta de produtos florestais, para diversos fins, representem uma fonte de renda alternativa real ou potencial para a população, além de proverem importantes recursos para a subsistência. Assim, índices de diversidade da paisagem podem auxiliar na indicação de paisagens com maior ou menor potencial para atividades que possam se constituir como elementos em um arranjo produtivo associados às atividades de uso da terra.

Para avaliar os diferentes contextos de uso da terra, esse trabalho tem como objetivo caracterizar as paisagens delimitadas pelas áreas no entorno das comunidades ribeirinhas e de terra firme, localizadas na porção sudoeste do estado do Pará, identificando regiões e grupos de comunidades inseridos em diferentes contextos de intensificação de uso da terra e de diversidade de paisagem e que, portanto, apresentam diferentes potenciais, para a sua entrada em arranjos produtivos em cadeias econômicas constituídas ou a se constituir, observados indiretamente pela relação dos indicadores da paisagem com a natureza dos meios de produção.

Índices de intensificação e de diversidade da paisagem foram desenvolvidos e aplicados para as áreas do entorno das comunidades, utilizando-se dados de uso e cobertura da terra do TerraClass-2012 (EMBRAPA; INPE, 2014), trabalhados em um agregado espacial na forma de células de $[8 \times 8] \mathrm{km}$ com o uso de técnicas de geoprocessamento. O indicador de intensificação foi desenvolvido com base nos modelos teóricos de Boserup (1970), Costa (2009) e Homma (2012) e a partir dos procedimentos metodológicos desenvolvidos por Souza et al (2015) e Souza (2016). O indicador de diversidade da paisagem utilizado baseou-se em uma métrica da paisagem, o Índice de Diversidade de Shannon (SHDI), que relaciona abundância (proporção de área) e a riqueza (número de classes) de classes de uso e cobertura da terra (MCGARIGAL; MARKS, 1995).

Os resultados obtidos permitem avaliar o entorno das comunidades do sudoeste paraense, quanto ao potencial econômico associado às atividades de uso e cobertura da terra, onde convivem sistemas produtivos como a agricultura de larga escala, a pecuária extensiva, a produção familiar e o extrativismo. Esses resultados podem 
fornecer subsídios para o planejamento econômico regional da Amazônia, apontando para as atividades de uso da terra que produzem paisagens mais diversificadas e, portanto, com maior potencial para construção de arranjos produtivos locais, que sejam inclusivos para as comunidades, e que possam participar em cadeias produtivas locais, regionais ou nacionais já existentes ou potenciais.

\section{ÁREA DE ESTUDO}

A área de estudo está localizada na porção sudoeste do estado do Pará, faz parte da Distrito Florestal Sustentável (DFS) da BR-163 e é delimitada pelos municípios de Santarém, Mojuí dos Campos, Belterra, Aveiro, Itaituba, Rurópolis, Placas, Uruará, Medicilândia e Brasil Novo. A área abrange comunidades ribeirinhas (59) e de terra firme (43) inseridas em distintos contextos de ocupação e de regimes de terra como, Unidades de Conservação (Reserva Extrativista do Tapajós-Arapiuns e Floresta Nacional do Tapajós), projetos de Assentamento do INCRA, Terras Indígenas e Projetos de Assentamentos Agroextrativistas (PAE). As comunidades ribeirinhas estão distribuídas ao longo do rio Tapajós e de seu afluente, o rio Arapiuns, enquanto que as comunidades de terra firme, localizam-se ao longo da rodovia Transamazônica (BR-230), no Planalto Santareno ${ }^{5}$, e algumas delas, ao longo da Br-163, como apresentado na área de estudo da figura 1.

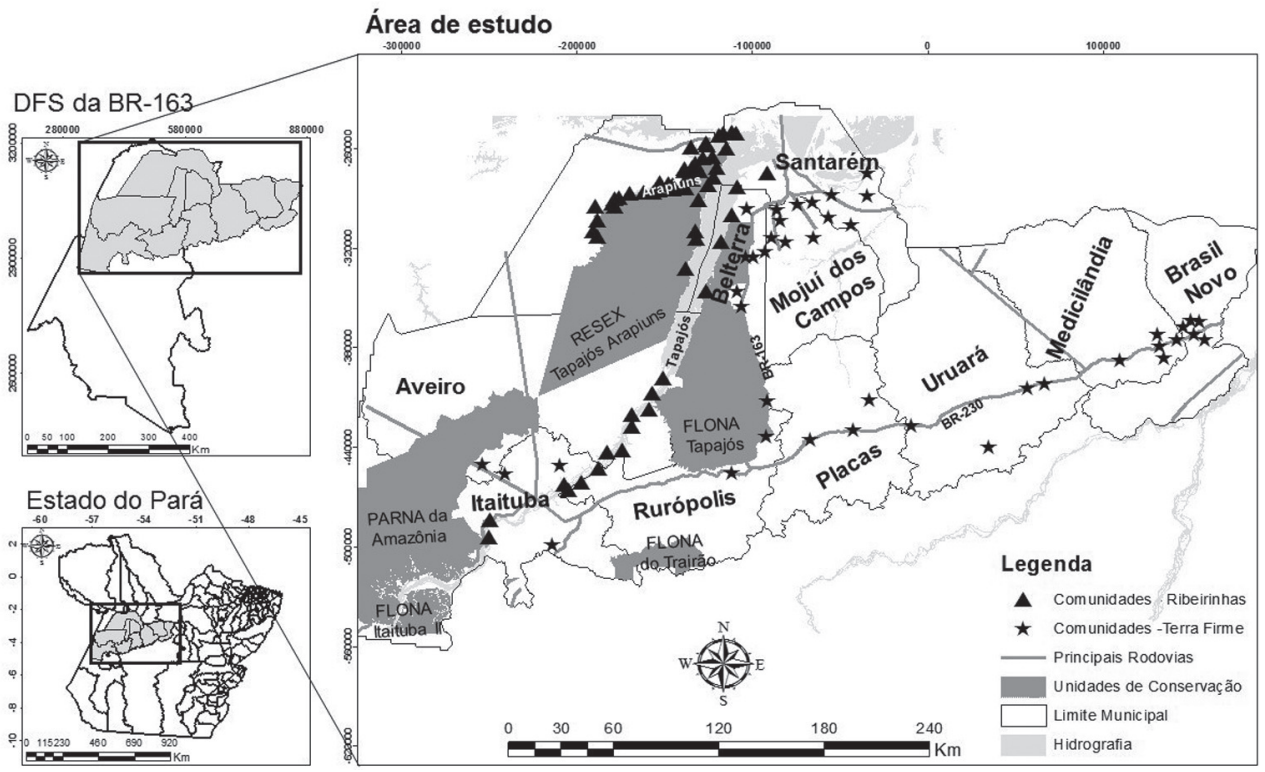

Figura 1 - Localização da área de estudo e das comunidades onde foram aplicados questionários semi-estruturados com resposta por informante-chave no Sudoeste Paraense

Fonte: Produção dos autores.

\footnotetext{
${ }_{5}$ Planalto Santareno: Constituído por um platô de terras firmes e altas, abrangendo os municípios de Santarém, Belterra e Mojuí dos Campos no Pará (SÁ et. al,2006).
} 


\section{MATERIAIS E MÉTODOS}

Os indicadores de intensificação e de diversidade da paisagem foram elaborados a partir de dados de uso e cobertura da terra do TerraClass-2012 (EMBRAPA e INPE, 2014), obtidos com imagens TM/Landsat-5 com resolução espacial de $30 \mathrm{~m}$ e refinados com dados de imagens do RapidEye ${ }^{6}$ com resolução espacial de 5 metros. 0 refinamento foi realizado de forma visual e consistiu na inclusão de uma nova classe do TerraClass, agricultura familiar de pequena escala, que representa o sistema de agricultura familiar. No refinamento, a classe mosaico de ocupações foi desagregada. Essa classe representa um mosaico de classes de uso e cobertura da terra, representadas por pequenos polígonos e agrupadas em uma única classe, em razão da limitação imposta pela resolução espacial de 30 metros do TM/Landsat-5 (EMBRAPA; INPE, 2014).

Os procedimentos metodológicos são apresentados nesta seção em quatro etapas: 1) refinamento do mapa de uso e cobertura da terra do TerraClass; 2) elaboração do indicador de intensificação do uso da terra; 3 ) elaboração de indicador de diversidade da paisagem e; 4) Análise integrada dos indicadores de intensificação e diversidade da paisagem. Em seguida, essas etapas são detalhadas.

\section{REFINAMENTO DOS DADOS DE USO E COBERTURA DA TERRA DO TERRACLASS}

O TerraClass-2012 (EMBRAPA; INPE, 2014) é um dado de uso e cobertura da terra, produzido a partir de dados da série Landsat e é composto pelas seguintes classes: vegetação secundária, pasto limpo, pasto sujo, pasto com solo exposto, regeneração com pasto, área urbana, área não observada, não floresta, hidrografia, agricultura anual, floresta, mineração, mosaico de ocupações, desflorestamento e outros. As classes contidas nos agrupamentos da classe mosaico de ocupações mapeados com o TM/Landsat-5 (30 metros), foram refinadas com as imagens do sensor REIS/RapiedEye-2 de 2011, 2012 e de 2014, com resolução espacial de 5 metros, que possibilitara identificar e mapear os usos e coberturas da terra incorporados à essa classe.

Para o refinamento foram utilizadas 49 imagens do RapidEye e 6 imagens do TM/Landsat-5, descritas na tabela 1.

\footnotetext{
${ }^{6}$ O RapidEye é constituído por uma constelação de 5 satélites em uma mesma órbita. E em cada um dos satélites estão instalados os sensores RapidEye Earth Imaging System (REIS). Os sensores dispõem de cinco bandas espectrais (azul, verde, vermelho, vermelho limítrofe (Red-Edge) e infravermelho próximo), com resolução espacial de 5 metros, resolução radiométrica de 12-bits (RapidEye, 2014).
} 


\section{Tabela 1- Cenas utilizadas do TM/Landsat-5 e RapidEye}

\begin{tabular}{|c|c|c|}
\hline Sensor & Ano & Órbita/ponto - Landsat \\
\hline \multirow[t]{2}{*}{ TM/Landsat-5 } & 2012 & $227 / 62,227 / 63,228 / 62,228 / 63,226 / 62$ e $226 / 63$ \\
\hline & & Identificador da imagem - RapidEye ${ }^{1}$ \\
\hline \multirow{3}{*}{ REIS/RapidEye-2 } & 2011 & $\begin{array}{l}2137225,2137322,2137325,2137327,2137726,2137825, \\
2137921 \text { e } 2137925 .\end{array}$ \\
\hline & 2012 & $\begin{array}{l}2137826,2138023,2138024,2137018,2137019,2137020, \\
2137119,2137120,2137220,2137221,2137225,2137226, \\
2137321,2137322,2137325,2137327,2137328,2137422, \\
2137522,2137723,2137724,2137725,2137726,2137820, \\
2137821,2137823,2137824,2137825,2137921,2137922, \\
2137923,2137924,21379252137523,2137622,2137623, \\
2137624,2137625,213721, \text { e } 2137927 .\end{array}$ \\
\hline & 2014 & 2137927. \\
\hline
\end{tabular}

Fonte: Produção dos autores.

As cenas utilizadas do RapidEye cobrem apenas as áreas do entorno das comunidades ribeirinhas e de terras firme e o tratamento das imagens foi realizado em duas etapas. Na primeira etapa, o pré-processamento das imagens foi realizado, considerando que as imagens do RapidEye e do TM/Landsat-5 (imagem de referên(ia) ${ }^{7}$ tem resoluções espacial distintas e necessitam de um corregistro entre elas. Pontos de controle foram adquiridos de forma manual e semiautomática e reamostrados pelo método do vizinho mais próximo. Foram utilizadas as bandas espectrais 3 (vermelho: 630 - $685 \mathrm{~nm}$ ),4 (vermelho limítrofe: 690 - $730 \mathrm{~nm}$ ) e 5 (infravermelho próximo: $760-850 \mathrm{~nm}$ ), visualizadas respectivamente nos canais, B (azul), R (vermeIho) $G$ (verde). Foi realizado o contraste linear nas bandas, com o objetivo de realçar os alvos de interesse nas imagens.

$\mathrm{Na}$ segunda etapa, foi realizada a classificação das imagens, adotando-se técnicas de interpretação visual e edição matricial em Sistema de Informação Geográfi$\mathrm{ca}^{8}$. Durante a fase de refinamento foram analisados atributos como forma, textura, cor, contexto e tamanho (NOVO, 2010) das feições de interesse. Para complementar, foram utilizados registros fotográficos georeferenciados armazenados na Fototeca do INPE (INPE, 2015) e levantados em expedições de campo (ESCADA et. al., 2013; DAL'ASTA et al., 2014). No processo de classificação, a identificação das classes baseou-se no dado do TerraClass e em alvos identificáveis dentro da classe mosaico de ocupações presentes na área de estudo. O mapa final compreendeu doze classes de uso e cobertura da terra listadas e descritas na tabela 2:

\footnotetext{
7 Foi utilizado o software TerraPixel-versão 1.04 (INPE, 2011).

8 Foi utilizado o SIG SPRING-versão 5.3 (CÂMARA et al, 1996).
} 


\section{Tabela 2 - Classes temáticas resultantes do refinamento doTerraClass-2012}

\begin{tabular}{l|l}
\hline \multicolumn{1}{c|}{ Classe } & \multicolumn{1}{c}{ Descrição } \\
\hline Floresta & $\begin{array}{l}\text { Área de floresta primária, indicada pelo PRODES e que não sofreu corte } \\
\text { raso. }\end{array}$ \\
\hline $\begin{array}{l}\text { Vegetação } \\
\text { Secundária }\end{array}$ & $\begin{array}{l}\text { Áreas que foram mapeadas como desmatadas pelo PRODES e que se } \\
\text { encontra em processo de regeneração natural. }\end{array}$ \\
\hline Pasto limpo & $\begin{array}{l}\text { Área de pastagem com ausência de vegetação arbórea e predomínio de } \\
\text { gramíneas. }\end{array}$ \\
\hline Pasto sujo & $\begin{array}{l}\text { Área de pastagem como predomínio de gramíneas e que apresenta } \\
\text { vegetação arbustiva esparsa, além de indivíduos arbóreos. }\end{array}$ \\
\hline $\begin{array}{l}\text { Pasto com solo } \\
\text { exposto }\end{array}$ & Área com baixa cobertura vegetal e solo exposto. \\
\hline $\begin{array}{l}\text { Regeneração } \\
\text { com pasto: }\end{array}$ & $\begin{array}{l}\text { Áreas que se encontram em processo de regeneração da vegetação } \\
\text { nativa, onde a cobertura é predominantemente arbustiva e arbórea. }\end{array}$ \\
\hline Área urbana: & Manchas de aglomerados populacionais, formando cidades ou vilas. \\
\hline $\begin{array}{l}\text { Agricultura de } \\
\text { pequena escala }\end{array}$ & $\begin{array}{l}\text { Área de agricultura itinerante fortemente baseada em um sistema de } \\
\text { agricultura familiar. }\end{array}$ \\
\hline Hidrografia & Reúnem distintos corpos d'água \\
\hline Outros & Reúnem bancos de areais, praias fluviais e afloramentos rochosos \\
\hline Não floresta & $\begin{array}{l}\text { Áreas de vegetação com fitos fisionômicos diferentes da vegetação do } \\
\text { bioma amazônico }\end{array}$ \\
\hline $\begin{array}{l}\text { Área não } \\
\text { observada }\end{array}$ & $\begin{array}{l}\text { Área não observada: Áreas com nuvens ou sombras, impossibilitando } \\
\text { identificar usos e coberturas da terra }\end{array}$ \\
\hline Fonte: adaptado de EMBRAPA e INPE (2008).
\end{tabular}

O TerraClass-2012, com o refinamento da classe mosaico de ocupações, denominado TerraClass2012-refinado, foi utilizado para a elaboração dos dois indicadores de intensificação do uso da terra e de diversidade da paisagem.

\section{INDICADOR DE INTENSIFICAÇÃO DO USO DA TERRA}

As classes de uso e cobertura da terra do TerraClass2012-refinado foram organizadas de acordo com o grau de intensificação, considerando uma associação dos conceitos de intensificação estabelecidos por Boserup (1970) e Homma (2012) e a definição das trajetórias tecnológicas estabelecidas por Costa (2009), operacionalizadas através da metodologia desenvolvida por Souza et al (2015) para a construção de um Gradiente de Intensificação de Uso da terra (GIU). Das classes que compõe o TerraClass2012-refinado foram selecionadas nove, que foram agregadas em sete grupos considerando, em ordem decrescente, os níveis de intensificação do uso da terra: 1) Área urbana e mineração; 2) Agricultura anual; 3) Agricultura de pequena escala; 4) Pasto limpo; 5) Pasto sujo; 6) Vegetação secundária e regeneração com pasto e; 7) Floresta.

As classes de pasto, vegetação secundária e floresta, são classes de cobertura e não de uso, mas permitem que alguma inferência sobre uso ou intensificação de uso seja feita. O uso inferido sobre as classes de pasto é a pecuária, cuja intensidade irá variar de acordo com o tipo de manejo realizado, inferido, por sua vez, pelo tipo de pasto apresentado, pasto limpo, pasto sujo, regeneração com pasto, etc. Essa é uma 
suposição plausível, pois a área analisada não é uma região de fronteira de ocupação ativa, onde a pastagem pode ser implantada como uma forma de assegurar a terra e não como base de um sistema produtivo. As classes floresta e vegetação secundária representam classes de cobertura da terra, entretanto, alguns usos podem ser inferidos a partir delas e também o nível de intensificação de uso. A vegetação secundária pode representar em grande parte, abandono, uma vez que o mapeamento dessa classe pressupõe que ela já sofreu corte raso (mapeado pelo PRODES) e, em algum momento, foi utilizada e abandonada. Nessa categoria pode haver também algum tipo de atividade extrativista (coleta de ervas medicinais, caça, etc.) ou produção por meio de sistemas agroflorestais, como o cultivo de cacau em consórcio com outras árvores para seu sombreamento. Na classe floresta o uso inferido é o extrativismo, supõe-se que toda cobertura florestal na área de estudo seja utilizada para o desenvolvimento dessa atividade. Essa suposição é baseada nas entrevistas com representantes chave das comunidades (ESCADA et al, 2013; DAL'ASTA et al.2014; AFFONSO et al., submetido em 2016), em que se observou que a grande maioria das populações ribeirinhas e de terra firme, desenvolvem alguma atividade extrativista (CAMILOTTI, 2016).

A classe hidrografia não foi computada neste índice, embora a atividade de pesca seja importante na região (CAMILOTTI, 2016). Para estabelecer relações entre os corpos d'água e níveis de intensidade e potencial para a atividade pesqueira, estudos específicos devem ser realizados, baseados em parâmetros hidrológicos e de qualidade de água que fogem dos paradigmas de intensificação de uso da terra estabelecidos por Boserup (1970), Homma (2012) e aqueles também tratados em Brondízio e Siqueira (1997).

Para obtenção do indicador de intensificação três etapas foram seguidas:

1. Elaboração de uma base de informação tendo como unidade espacial de referência uma célula regular (polígono) de $[8 \times 8] \mathrm{km}$, denominada espaço celular, onde é possível, para cada célula, calcular a porcentagem de cada classe $^{9}$ de uso e cobertura da terra para os dados do TerraClass2012-refinado. Essa resolução espacial foi definida em função das distâncias máximas percorridas pela população das comunidades para desenvolvimento de atividades extrativistas, como, por exemplo, caça, (PEREIRA; FABRÉ, 2009; RAMOS, 2013) e atividades agropecuárias. Essas atividades se dão nas proximidades da moradia até aproximadamente $7,5 \mathrm{~km}$ de distância, de acordo com levantamentos de campo na região, relatados por Escada et al. (2013) e Dal'Asta et al. (2014);

2. Conversão do espaço celular para uma grade regular de resolução espacial [8x8] km utilizando o atributo porcentagem de cada classe, calculado na etapa anterior, em que cada célula passa a ser representada como um ponto na grade regular, com valores que variam de 0 a 100 ;

3. O cálculo dos pesos das classes utilizando a média ponderada com auxílio da AHP (Analytic Hierarchy Process) (SAATY, 1980). A AHP foi utilizada para definir o grau de intensificação (pesos) de cada classe de uso e cobertura da terra, onde os diferentes critérios de importância foram atribuídos às classes, com base no conhecimento do especialista sobre os sistemas produtivos presentes na região de estudo e no conceito de intensificação utilizado.

\footnotetext{
${ }_{9}$ Foi utilizado o plugin de preenchimento de célula do TerraView- versão 4.2.2 (TerraView, 2010).
} 
Com base na escala de Comparação de Critérios desenvolvida por Saaty (1980) adaptada para o contexto da intensificação (Tabela 3 ) foi construída uma matriz de comparação pareada. A comparação é feita classe a classe, na qual a relação de importância entre as classes é obtida a partir de critérios baseados no conhecimento das atividades produtivas locais e no conceito de intensificação estabelecido. Ao comparar duas classes como, Agricultura anual com Floresta, foi atribuída a essa relação o valor 8, que significa que, em paisagens com áreas de Agricultura anual, a intensificação é criticamente maior que em áreas de Floresta.

\section{Tabela - 3 Escala de Comparação de Critérios}

\begin{tabular}{c|l}
\hline Escala numérica & \multicolumn{1}{c}{ Definição } \\
\hline $1 / 9$ & Absolutamente menos intensificado \\
\hline $1 / 7$ & Criticamente menos intensificado \\
\hline $1 / 6$ & Bem menos intensificado \\
\hline $1 / 5$ & Menos intensificado \\
\hline $1 / 4$ & Moderadamente menos intensificado \\
\hline $1 / 3$ & Pouco menos intensificado \\
\hline $1 / 2$ & Pouco intensificado \\
\hline 1 & Intensificação igual \\
\hline 2 & Intensificação um pouco maior \\
\hline 3 & Intensificação moderada \\
\hline 4 & Intensificação moderadamente maior \\
\hline 5 & Intensificação maior \\
\hline 6 & Intensificação bem maior \\
\hline 7 & Intensificação muito maior \\
\hline 8 & Intensificação criticamente maior \\
\hline 9 & Intensificação absolutamente maior \\
\hline Fonte: adaptado de & Saaty (1980) \\
\hline
\end{tabular}


A tabela 4, apresenta o pareamento realizado entre as classes. A Razão de Consistência, quando menor ou igual a 0,1, é dada por Saaty (1980) como satisfatória, demonstrando que a comparação pareada entre as classes de uso e cobertura da terra é consistente.

\section{Tabela 4 - Matriz de comparação pareada das classes de uso e cobertura da terra}

\begin{tabular}{|c|c|c|c|c|c|c|c|}
\hline \multicolumn{8}{|c|}{ Referência } \\
\hline $\begin{array}{c}\text { Classes de } \\
\text { uso e } \\
\text { cobertura } \\
\text { da terra }\end{array}$ & $\begin{array}{l}\text { Área } \\
\text { urbana e } \\
\text { mineração }\end{array}$ & $\begin{array}{l}\text { Agricultura } \\
\text { anual }\end{array}$ & $\begin{array}{l}\text { Agricultura de } \\
\text { pequena } \\
\text { escala }\end{array}$ & $\begin{array}{l}\text { Pasto } \\
\text { limpo }\end{array}$ & $\begin{array}{l}\text { Pasto } \\
\text { Sujo }\end{array}$ & $\begin{array}{l}\text { Vegetação } \\
\text { secundária e } \\
\text { regeneração } \\
\text { com pasto }\end{array}$ & Floresta \\
\hline $\begin{array}{l}\text { Área urbana e } \\
\text { mineração }\end{array}$ & 1 & 2 & 3 & 4 & 6 & 7 & 9 \\
\hline $\begin{array}{l}\text { Agricultura } \\
\text { anual }\end{array}$ & $1 / 2$ & 1 & 4 & 4 & 5 & 7 & 8 \\
\hline $\begin{array}{l}\text { Agricultura de } \\
\text { pequena } \\
\text { escala }\end{array}$ & $1 / 3$ & $1 / 4$ & 1 & 2 & 5 & 6 & 7 \\
\hline Pasto limpo e & $1 / 4$ & $1 / 4$ & $1 / 2$ & 1 & 5 & 6 & 7 \\
\hline Pasto Sujo & $1 / 6$ & $1 / 5$ & $1 / 5$ & $1 / 5$ & 1 & 2 & 4 \\
\hline $\begin{array}{l}\text { Vegetação } \\
\text { secundária e } \\
\text { regeneração } \\
\text { com pasto }\end{array}$ & $1 / 7$ & $1 / 7$ & $1 / 6$ & $1 / 6$ & $1 / 2$ & 1 & 2 \\
\hline Floresta & $1 / 9$ & $1 / 9$ & $1 / 7$ & $1 / 7$ & $1 / 4$ & $1 / 2$ & 1 \\
\hline
\end{tabular}

Fonte: Produção dos autores

Com as informações fornecidas pela combinação pareada atribuiu-se pesos a cada classe, de acordo com o grau de intensificação, A tabela 5 apresenta as classes com seus respectivos pesos.

\section{Tabela 5 - Pesos atribuídos a cada classe utilizando a AHP}

\begin{tabular}{l|l}
\hline \multicolumn{1}{c|}{ Classes de uso e cobertura } & Pesos \\
\hline Área urbana e mineração & 0,306 \\
\hline Agricultura anual & 0,286 \\
\hline Agricultura de pequena escala & 0,159 \\
\hline Pasto limpo & 0,141 \\
\hline Pasto Sujo & 0,055 \\
\hline Vegetação secundária e regeneração com pasto & 0,033 \\
\hline Floresta & 0,022 \\
\hline
\end{tabular}

Fonte: Produção dos autores. 
Com os pesos estimados pela técnica AHP foi realizada a operação de média ponderada (Equação 1). Os pesos foram aplicados a grade regular de cada classe de uso e cobertura da terra, obtendo-se como resultado, o GIU - Gradiente de Intensificação do Uso da Terra.

$$
G I U=\frac{\sum_{i=1}^{7} C_{i} \cdot P_{i}}{\sum_{i=1}^{7} P_{i}}
$$

Onde :

$C_{i}$ é a classe $i$

$P_{i}$ é o peso da classe $i$

\section{INDICADOR DE DIVERSIDADE DA PAISAGEM}

O Indicador de Diversidade da Paisagem (IDP) considera todas as classes de uso e cobertura da terra, com potencial de uso pela população. As classes selecionadas foram reunidas em nove grupos: 1) Área urbana; 2) Mineração; 3) Agricultura anual; 4) Agricultura de pequena escala; 5) Pasto limpo e pasto sujo (pastagens); 6) Vegetação secundária e regeneração com pasto; 7) Floresta; 8) Hidrografia; 9) Outros, desflorestamento e não floresta

As classes outros, desflorestamento e não floresta, foram consideradas por representarem diferentes tipos de cobertura da terra, enquanto as áreas não observadas, representam ausência de informação, por isso não foram analisadas,

Para o cômputo do indicador, os procedimentos foram divididos em duas etapas:

1. Foi construída uma base celular de $[8 \times 8] \mathrm{km}$ de resolução espacial, na qual foi calculada a porcentagem de área de cada classe (medida de abundância) por célula. Esta etapa se assemelha ao procedimento desenvolvido na elaboração do indicador de intensificação do uso da terra.

2. Cálculo do Índice de Diversidade de Shannon. Este índice considera as métricas de paisagem riqueza e abundância. A riqueza corresponde ao número de classes de uso e cobertura e abundância corresponde a proporção ocupada por cada classe de uso e cobertura da terra presentes na paisagem (MCGARIGAL, 1996). Na Equação 2 é apresentando o Índice de Diversidade de Shannon (SHDI), dado por:

Onde:

$$
S H D I=-\sum_{i=1}^{m}(P i \cdot \ln P i)
$$

$m$ é o número de classes de uso e cobertura da terra;

Pi é a proporção da paisagem ocupada pelas classes de uso e cobertura;

$i$ são as classes de uso e cobertura.

O Índice de Diversidade de Shannon varia de 0 infinito. Quando este índice se aproxima de 0 , indica que há apenas uma cobertura, que domina a paisagem. Quanto maior o valor obtido com esse índice, maior é a diversidade da paisagem e, consequentemente, menor é dominância de classes (MCGARIGAL, 1996). 


\section{INTEGRAÇÃO DOS INDICADORES DE INTENSIFICAÇÃO E DE DIVERSIDADE DA PAISAGEM}

Para caracterizar a área de estudo em relação à intensificação e à diversidade, as grades regulares (MNT) dos indicadores de intensificação e de diversidade foram transformadas em imagens mantendo a mesma resolução espacial com auxílio de um Sistema de Processamento de Imagens. Essa operação permite que cada indicador seja associado a um canal de banda do sistema de cores RGB (Red - vermelho; Green- verde e Blue-azul).

Após a transformação, para compatibilização da imagem dos indicadores, os valores foram normalizados, aplicou-se uma transformação linear, passando os valores das imagens para a escala entre 0 e 1.

Em seguida, foi realizada uma composição de bandas. Neste caso, como são duas imagens, foram escolhidos dois componentes, o R e o G, na qual o indicador de intensificação do uso da terra foi associado ao canal vermelho $(R)$ e o de diversidade da paisagem ao canal verde (G). Para facilitar a interpretação da imagem obtida com a composição RG, foi estabelecida uma legenda com 4 categorias:

1. Alto-Baixo, representando um alto valor de GIU e baixo valor de IDP. A composição colorida desses dois indicadores no mapa é representada pela cor amarelo escuro, tendendo para o laranja;

2. Alto-Alto, representando um alto valor de intensificação (GIU) e alto valor de diversidade da paisagem (IDP). Esta composição aparece no mapa em amarelo;

3. Baixo-Alto, representando um baixo valor de GIU alto valor de IDP. A composição entre as cores dos dois indicadores é representada no mapa pela cor verde em várias tonalidades;

4. Baixo-Baixo, representando um baixo valor de GIU e de IDP. Como os valores de ambos os indicadores são próximos de 0 , a composição das cores aparece no mapa em tons escuros.

Complementarmente, foram utilizados dados da produção agropecuária e de produtos extrativistas para caracterizar as comunidades em função do seu potencial para inserção em arranjos produtivos, considerando as categorias definidas pela integração da intensificação e diversidade da paisagem. Esses dados foram coletados em expedições de campo de 2011 a 2015 (ESCADA et al, 2013; DAL'ASTA et al,2014; AFFONSO et al., submetido em 2016), onde foram aplicados questionários semiestruturado a informantes chave com questões relacionadas com o uso da terra e com os produtos extrativistas de origem vegetal e animal (PEVAS). A escolha do tipo de produção e do produto estão relacionadas com as atividades que são importantes para manutenção das comunidades, organizadas em consumo e venda, apresentadas na tabela 6 .

Para a análise foram selecionadas 102 comunidades, 43 de terra firme e 59 ribeirinhas, distribuídas ao longo dos rios Tapajós e de seu afluente, o Rio Arapiuns (CARDOSO; MONTEIRO, 2014). 


\section{Tabela 6- Produção e produtos relacionados} com o uso da terra e PEVAS

\begin{tabular}{c|l|l}
\hline Destino & Atividade & Descrição \\
\hline \multirow{4}{*}{ Consumo } & $\begin{array}{l}\text { Produção } \\
\text { agropecuária }\end{array}$ & $\begin{array}{l}\text { Carne e leite, farinha, arroz, feijão, macaxeira, milho, } \\
\text { pimenta e frutas }\end{array}$ \\
\cline { 2 - 3 } & $\begin{array}{l}\text { Produtos } \\
\text { extrativistas }\end{array}$ & $\begin{array}{l}\text { Borracha, carne de caça, produtos medicinais, peixe, } \\
\text { madeira, artesanato e castanha do Pará }\end{array}$ \\
\hline \multirow{4}{*}{ Venda } & $\begin{array}{l}\text { Produção } \\
\text { agropecuária }\end{array}$ & $\begin{array}{l}\text { Carne e leite, farinha, frutas, cacau e roça. As } \\
\text { atividades de roça são representadas por arroz, feijão, } \\
\text { macaxeira e milho. }\end{array}$ \\
\cline { 2 - 3 } & $\begin{array}{l}\text { Produtos } \\
\text { extrativistas }\end{array}$ & $\begin{array}{l}\text { Borracha, carne de caça, produtos medicinais, peixe, } \\
\text { madeira e artesanato }\end{array}$ \\
\hline
\end{tabular}

Fonte: Produção dos autores.

\section{RESULTADOS E DISCUSSÃO}

Na área estudada, observou-se que a classe floresta (6.988.848ha) somada com a classe vegetação secundária (824.850ha) ocupa um pouco mais de $80 \%$ da área de estudo. Estas classes dominam a paisagem e estão localizadas em áreas ribeirinhas, principalmente nas áreas de Unidades de Conservação, como a RESEX ${ }^{10}$ do Tapajós-Arapiuns, a FLONA ${ }^{11}$ do Tapajós, o PARNA ${ }^{12}$ da Amazônia, a FLONA Itaituba II e a FLONA do Trairão. Nas áreas desmatadas pouco mais de $27 \%$ são constituídas por pastagens representadas pelas classes pasto limpo ( 513.432 ha) e pasto sujo (195.538 ha), localizadas principalmente na região do Planalto Santareno, na rodovia Transamazônica, no entorno de Itaituba e, em menor proporção, na região dos rios Arapiuns e Tapajós. A tabela 7 apresenta as classes de uso e cobertura da terra das áreas desmatadas referente a área de estudo.

Tabela 7- Proporção de cada classe de uso e cobertura da terra presentes na área de estudo

\begin{tabular}{l|c|c}
\hline \multicolumn{1}{c|}{ Classes } & Hectares & \% \\
\hline Vegeteção Secundária & 824.850 & 31.1 \\
\hline Hidrografia & 544.202 & 20.5 \\
\hline Pasto limpo & 513.432 & 19.4 \\
\hline Área não observada & 222.406 & 8.4 \\
\hline Pasto sujo & 195.538 & 7.4 \\
\hline Regereneração com pasto & 179.490 & 6.8 \\
\hline Não floresta & 749.98 & 2.8 \\
\hline Agricultura Anual & 351.34 & 1.3 \\
\hline Desflorestamento & 251.75 & 0.9 \\
\hline Área urbana & 202.54 & 0.8 \\
\hline Outros & 110.09 & 0.4 \\
\hline Agricultura de pequena escala & 511.4 & 0.2 \\
\hline Mineração & 263 & 0.0 \\
\hline
\end{tabular}

Fonte: TerraClass2012-refinado.

10 RESEX : Reserva Extrativista

11 FLONA: Floresta Nacional

12 PARNA: Parque Nacional 
Embora a classe agricultura anual, represente menos de 1,5\% da área de estudo, observou-se que a maior parcela da classe, aproximadamente $96 \%$, está concentrada na região do Planalto Santareno (337,82 ha) e em proporções bem menores, apenas 4\%, na porção norte do município de Uruará (135,2 ha). Essa área localiza-se no extremo norte do município (INPE, 2015) e distante da rodovia Transamazônica, onde predominam a agricultura familiar e a pecuária. A concentração da atividade agrícola de larga escala é maior na região do Planalto Santareno devido à condição do relevo que favorece a mecanização, além da infraestrutura que a região disfruta como, estradas pavimentadas, principalmente a BR-163 que liga Cuiabá-Santarém, e o porto graneleiro da Cargill, inaugurado em 2003 (SÁ et al, 2006; DAL'ASTA, 2013; NAHUM; PAIXÃO JÚNIOR, 2014).

Complementar a análise do entorno das comunidades, a figura 2 apresenta o indicador de intensificação do uso da terra, denominado neste trabalho de Gradiente de Intensificação do Uso da terra (GIU). O GIU na área de estudo, varia de 0,0 a 11,3. O valor 0,0 corresponde as áreas não intensificadas, como as áreas de remanescentes florestais, enquanto o valor 11,3 corresponde as áreas com maior grau de intensificação como, por exemplo, áreas de agricultura anual.

As áreas que apresentam maior intensificação de uso estão espacialmente concentradas na região do Planalto Santareno, entre os municípios de Santarém, Mojuí dos Campos e Belterra, bem como, em pequenos trechos da rodovia Transamazônica (BR-230), principalmente no entorno das sedes dos municípios localizados no eixo dessa rodovia, com destaque para Itaituba.

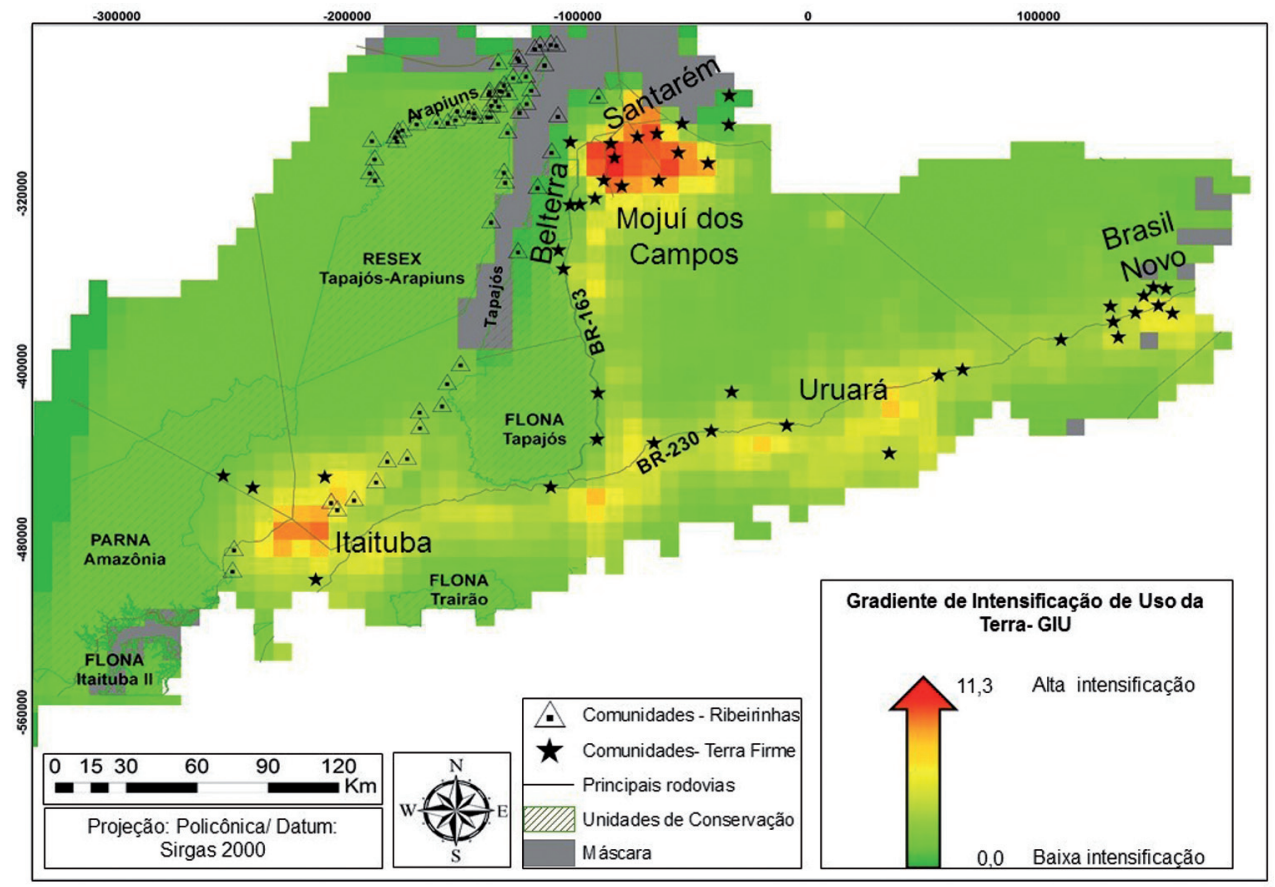

Figura 2 - Gradiente de Intensificação do Uso da terra (GIU)

Fonte: Produção dos autores. 
A intensificação do uso da terra apresentada na região do Planalto Santareno, entre Santarém, Mojuí dos Campos e Belterra, está relacionada com a agricultura anual de larga escala (agronegócio), podendo ser atribuída principalmente ao cultivo de grãos, em especial a soja (OLIVEIRA et al, 2013; WALKER et al, 2013). Este sistema produtivo incorpora grandes extensões de terras e o uso intensivo de tecnologias como, mecanização, melhoramento genético (semente combinada com fertilizantes) e técnicas de plantios (adubos químicos, corretivos do solo e defensivos agrícolas) visando o aumento da produtividade e a redução de custos, principalmente com mãode-obra (OLIVEIRA et al, 2013).

Na rodovia Transamazônica (BR-230) a intensificação é particularmente observada devido às atividades agropecuárias. O município de Itaituba é o que mais se destaca por apresentar um alto grau de intensificação. A região de Uruará, embora apresente alguma produção de grãos, a área de plantio observada é muito pequena, corresponde a 670 hectares (IBGE,2015a), e localiza-se distante do eixo da Transamazônica. No Planalto Santareno a área plantada chega a 40.632 hectares (IBGE, 2015a). No entorno de Itaituba é onde estão concentradas maiores áreas de pastagens, por isso o grau de intensificação é mais alto do que nas demais áreas. A pastagem é a classe predominante nesta paisagem, e é voltada tanto para o corte quanto para a produção leiteira (SENA et al,2012). A produção leiteira é destinada ao consumo e aos laticínios de pequeno porte, instalados em Itaituba e em outras cidades na Transamazônica como, Placas e Rurópolis (SENA et al,2012). Mas é em Itaituba que a criação de gado é mais expressiva, o efetivo bovino no município chega a 344.197 cabeças (IBGE, 2014b). Enquanto em Rurópolis e Placas o número de efetivo dos rebanhos é menor, 142.087 cabeças em Rurópolis e em Placas 127.830 cabeças (IBGE, 2014b).

Pode ser observado tanto no Planalto Santareno quanto na região de Itaituba que os índices de intensificação mais altos se encontram nas áreas mais próximas a sede do município centro urbano. Essa classe influencia o índice de intensificação, pois foi atribuído a esta classe o peso mais alto na hierarquia construída.

A medida que nos afastamos dos centros urbanos, o índice de intensificação vai diminuindo, estabelecendo áreas com menor grau de intensificação. Isso pode ser observado na borda do Planalto Santareno e na rodovia Transamazônica, nos travessões e vicinais próximos ao eixo da rodovia. Este padrão se relaciona principalmente com as atividades desenvolvidas pela agricultura familiar como os cultivos de milho, feijão, arroz, mandioca, macaxeira, banana, criação de pequenos rebanhos de gado e cultivo de cacau (DAL'ASTA et al, 2014). A produção de cacau é uma das atividades mais presentes nas proximidades da rodovia Transamazônica, como observado nos levantamentos de campo (ESCADA et al, 2013; DAL'ASTA et al.2014).

Nas áreas de Unidades de Conservação e nas margens do Tapajós e de seu afluente, o rio Arapiuns, locais mais afastados das rodovias e das áreas urbanas, predominam as células com índice de intensificação mais baixo, próximo de 0 . São regiões que apresentam áreas mais contínuas de remanescentes florestais e de vegetação secundária, que se caracterizam pelo desenvolvimento da agricultura itinerante, com o cultivo de mandioca para a produção de farinha, com uma produtividade mais baixa do que áreas de produção de grãos no Planalto Santareno e um baixo uso de tecnologia e mão de obra qualificada. Além disso, devido às proximidades com a floresta primária, secundária e com o rio, podem ocorrer atividades extrativistas como, coleta de produtos florestais e a pesca, provendo alimentos e produtos medicinais (ESCADA et al, 2013; DAL'ASTA et al, 2014).

Os valores mais altos do índice de intensificação do uso da terra podem ser verificados particularmente em áreas de produção de grãos, onde os produtores se especializam cada vez mais, investindo e incorporando tecnologia a fim de aumentar 
sua eficiência produtiva. Este modelo de agricultura é voltado para a exportação e reduz a quantidade de terras disponíveis para a produção de alimentos para abastecimento local (SANTOS et al, 1997).

O estágio de intensificação do Planalto Santareno, em especial em Santarém, está em processo inicial quando comparado com outras regiões onde o agronegócio está fortemente consolidado como, por exemplo, Lucas do Rio Verde no Mato Grosso. Em Lucas do Rio Verde este processo, comandado pelos empresários-produtores e pelas políticas públicas nas três esferas de governo, federal, estadual e municipal, incentivaram o estabelecimento de um polo agroindustrial, em conjunto com a melhoria da infraestrutura de transporte e a infraestrutura urbana. Como resultado, o agronegócio foi fortalecido nesta região, estabelecendo um mercado totalmente voltado para exportação resultando também na diminuição da população rural (CRAICE e LOMBARDI, 2014). O censo de 2010 (IBGE,2010) mostra que o município tem $2 \%$ de sua população vivendo em domicílios rurais, enquanto Santarém apresenta mais de $27 \%$. Santarém, ao receber maiores investimentos e incorporação de infraestrutura ao agronegócio, como os portos previstos em Itaituba e a linha férrea planejada, poderá vir a elevar o grau de intensificação de sua área e, consequentemente, sofrer maior pressão sobre as terras da agricultura familiar ou as terras de produção tradicional, o que pressiona para um modelo que força a maior concentração de terras e a exclusão dos pequenos produtores da possibilidade de acesso aos novos circuitos econômicos em formação (CANUTO, 2004; OLIVEIRA; SANTANA, 2012; NAHUM; PAIXÃO JÚNIOR, 2014).

Em oposição as áreas de maior intensificação, nas áreas onde o grau de intensificação é menor, predomina a agricultura familiar para subsistência que eventualmente comercializa o excedente da produção e, as atividades extrativistas e alguma pecuária, geralmente com pouca ou nenhuma assistência técnica, baixa organização e estruturação da cadeia, baixa associatividade gerando uma agricultura, extrativismo ou pecuária com baixo nível tecnológico e, como consequência, baixa produtividade. Embora, possamos observar nesses sistemas uma produção mais diversificada, muitas vezes com o cultivo realizado com sistema de rotação e pousio ou, mais raramente, com consorciação de culturas, o que mostra o potencial para o seu pleno desenvolvimento como atividade econômica se as condições de estruturação para promover APLs fosse, de alguma forma, construída.

Em oposição à intensificação, na figura 3 é apresentando o indicador de diversidade da paisagem (IDP), identificado a partir das classes de uso e cobertura da terra do TerraClass2012-refinado e da aplicação do Índice de Diversidade de Shannon. O IDP foi ordenado de modo que o grau mais baixo representa o intervalo de 0 a 0,22 , representando a baixa diversidade de uso e cobertura da terra. E o grau mais alto do índice corresponde ao intervalo entre 1,35 e 1,58, indicando as áreas com maior diversidade de uso e cobertura da terra.

A partir do indicador de diversidade, observou-se que algumas regiões apresentaram uma diversidade alta, entre 1,35 e 1,58, destacando-se entre elas, parte do Planalto Santareno, às margens do rio Tapajós, próximas da região de Itaituba, na região do rio Arapiuns e na foz do rio Tapajós. Esse indicador poderia chegar a valores mais altos, não havendo um limite superior, entretanto, a região, de uma forma geral, não apresenta uma grande diversidade de classes de cobertura da terra, apresentando dominância quase sempre das áreas de pastagem ou de floresta, por essa razão, o valor máximo encontrado foi de apenas 1,58. As áreas que apresentaram índices mais baixos, entre 0 e 0,22, representam as áreas de Unidades de Conservação e áreas de difícil acesso, com dominância de floresta. 


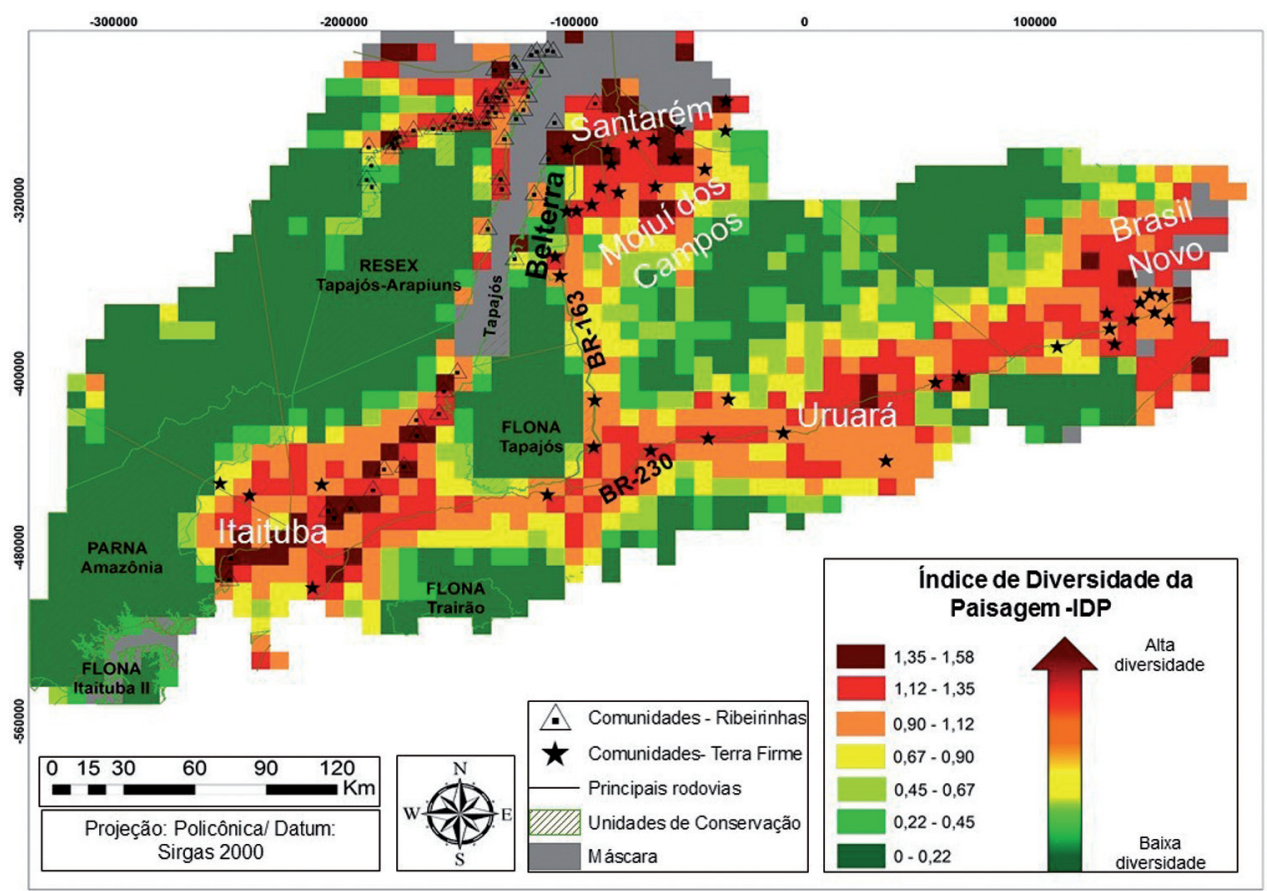

Figura 3 - Indicador de Diversidade da Paisagem - IDP

Fonte: Produção dos autores.

No Planalto Santareno este padrão pode ser explicado devido ao histórico de ocupação da região em que, até o final da década de 90 , predominavam os pequenos produtores rurais e algumas áreas de fazenda dedicadas à pecuária (CÔRTES; D'ANTONA, 2010). Muitos dos lotes e fazendas foram vendidos para a implantação do agronegócio no início da década de 2000 (CÔRTES; D'ANTONA, 2010). Entretanto, durante expedições de campo (DAL'ASTA et al, 2014), constatou-se que muitos agricultores ainda persistem na região, em pequenos lotes rurais, coexistindo, assim, com os grandes produtores. No trabalho de Dal'Asta et al, (2014), realizado na região do entorno de Santarém, para os anos de 1990, 1999 e 2010, são apresentados seis tipos de padrões de ocupação, dois deles relacionados com atividades de pequenos produtores rurais e da agricultura familiar e um padrão misto que inclui atividades de grandes, médios e pequenos produtores, associados ao agronegócio, a pecuária e a agricultura familiar, respectivamente. Os autores observaram a expansão dos padrões relacionados com o agronegócio e a redução dos padrões associados aos pequenos produtores rurais entre os períodos analisados. Vale ressaltar a existência de um outro processo observado nos estudos de Santos et al, (1997) e D'Antona et al, (2011) nessa região. Ao passo que áreas dos pequenos produtores são incorporadas pelo agronegócio, aumentando a concentração fundiária, algumas áreas são fragmentadas, devido ao desmembramento dos lotes, pois, à medida que os filhos se casam e formam novos núcleos familiares, os lotes rurais são divididos, formando lotes menores. Assim, apesar da emergência dos grandes talhões de agricultura anual e pastagem no Planalto Santareno, ainda se manifestam na paisagem os padrões espaciais relacionados com a agricultura familiar, e junto a eles, a vegetação secundária e a floresta. 
Os pequenos agricultores dedicam-se mais a venda dos produtos agropecuários, como a farinha, o gado-corte e leite, e o cultivo de lavoura- mandioca, milho, feijão e arroz. O agronegócio demanda projetos de infraestrutura física, principalmente de estradas pavimentas para escoamento da produção. Como a região dispõe dessa infraestrutura, isso beneficia os pequenos produtores rurais que a utilizam para o escoamento de sua produção até os centros de comercialização (SÁ et al, 2006; DAL'ASTA et al, 2014; ).

Na região de Itaituba, no entorno das comunidades ribeirinhas do Tapajós, algumas células concentram os valores mais altos do indicador de diversidade, entre 1,35 e 1,58. Embora, a classe predominante na paisagem seja a pastagem, fortemente associada à pecuária de corte e leiteira (SENA et al, 2013), entremeadas a esta classe, existem áreas de floresta, vegetação secundária, áreas de agricultura de pequena escala, corpos d'água e os grandes talhões de pastagem. As comunidades ribeirinhas de Itaituba que não tiveram suas terras incorporadas à pecuária intensiva, ainda realizam práticas agropecuárias seguindo o modelo de pequena escala, com o cultivo de arroz, feijão, milho, a produção de farinha e a pecuária extensiva (DAL'ASTA et al, 2014).

As bordas das Unidades de Conservação - FLONA-Tapajós e RESEX-TapajósArapiuns, principalmente aquelas localizadas na faixa ribeirinha dos rios Tapajós e Arapiuns, destacaram-se por apresentarem um padrão diferente daquele encontrado na paisagem intensificada. Nestas áreas pode ser observada a ocorrência de valores altos do índice de diversidade da paisagem, nos intervalos entre 0,90 e 1, 58. Este padrão está relacionado com a heterogeneidade do uso e cobertura da terra, devido à presença de áreas de floresta, vegetação secundária, pastagens, agricultura familiar e hidrografia. Nesta região, a população ribeirinha trabalha na terra seguindo o modelo de agricultura itinerante, com atividades baseadas na produção alimentar, com lavouras de mandioca, milho, feijão e plantios de hortaliças, produção de farinha, criação de gado, pesca e extrativismo.

A região com índice mais baixo de diversidade compreende o intervalo entre 0 e 0,22. Estas áreas estão localizadas dentro das áreas de Unidades de Conservação e de floresta primária, resultando na alta homogeneidade do uso e cobertura da terra e, consequentemente, da dominância da classe floresta, que possibilita atividades extrativistas.

Os indicadores propostos, Intensificação da Paisagem (GIU) e de Diversidade da Paisagem (IDP), em separado, propiciaram leituras sobre diferentes dimensões associadas aos sistemas produtivos e sua expressão territorial na área estudada. Permitiram, a partir da observação indireta da estrutura da paisagem com o uso de sensoriamento remoto e a construção de métricas de paisagem, a produção de um mapa de GIU - Gradiente de Intensificação e de um mapa de Diversidade da Paisagem, que se constituíram enquanto cartografias de mediação, permitindo um diálogo com a literatura sobre a região e com estudos de campo, bem como, refletir sobre as possibilidades e limitações para o estabelecimento de estratégias de desenvolvimento econômico inclusivas.

A integração destas duas dimensões, intensificação e diversidade, através da construção de uma representação única, nos permite acompanhar a dinâmica do comportamento de processos distintos, porém, associados. Quando analisados conjuntamente, de forma integrada, o que esperamos encontrar são células de maior intensificação de usos gerando paisagens com menor diversidade, composição esperada para a região do Planalto Santareno. Dal'Asta et al (2013), por exemplo, ao analisarem trajetórias de mudanças de padrões de uso da terra no período de 1990 a 2010, encontraram uma mudança bastante significativa na estruturação espacial dos arranjos das classes de uso e cobertura da terra, devido à concentração espacial, 
especificamente na área de produção mecanizada de grãos e de pecuária de grande porte. D'Antona et al (2011) realizaram levantamentos de campo em mais de 500 lotes desta região e observaram padrão similar de concentração fundiária no período de 1970 a 2003. Assim, seria de se esperar que nessas áreas ocorresse a dominância das coberturas associadas às atividades ligadas ao agronegócio, e à pecuária, de maior escala, produzindo uma paisagem mais homogênea, portanto, pouco diversificada.

Entretanto, os resultados da análise conjunta dos indicadores mostraram algumas surpresas nos padrões e comportamentos esperados, como observado na figura 4. Com o uso desta representação, quatro classes foram estabelecidas, de acordo com a integração dos índices de intensificação e diversidade da paisagem: 1. GIU alto e IDP baixo; 2. GIU alto e IDP alto; 3. GIU baixo e IDP alto; 4. GIU baixo e IDP baixo. Os padrões encontrados nessas classes são descritos e com eles uma discussão é apresentada para jogar alguma luz nos resultados encontrados.

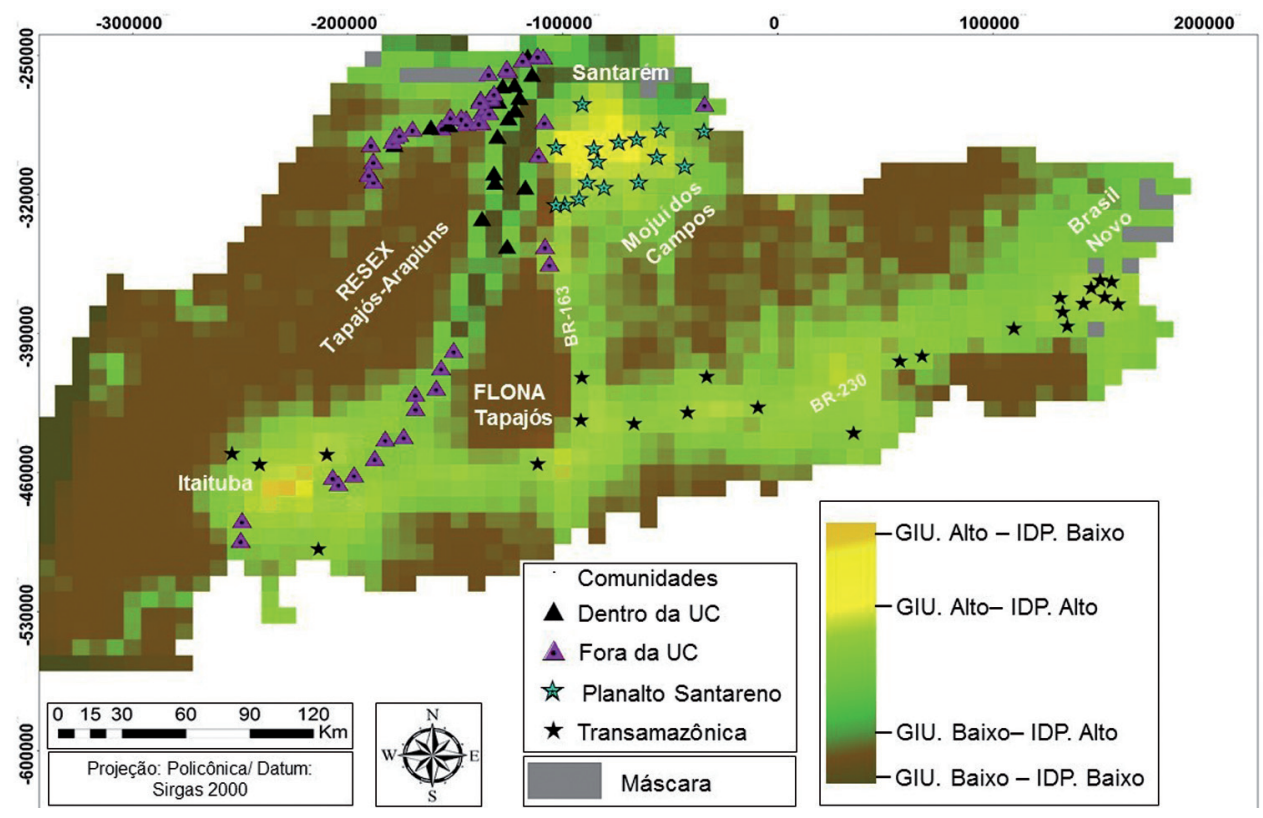

\section{Figura 4 - Integração dos indicadores de intensificação do uso da terra e de diversidade da paisagem}

Fonte: Produção dos autores.

\section{GIU alto e IDP baixo}

Foi observado na figura 4, que a classe GIU alto e IDP baixo, é pouco evidente na área de estudo. Este padrão foi observado em apenas duas células de [8x8] km no entorno de Itaituba, associado à dominância da classe pastagem. Embora nessa região a pecuária seja extensiva, estudos desenvolvidos por Rivero et al (2009) e Walker et al (2013), além do próprio dado do TerraClass (2012), apontam que a maior parte da conversão de floresta na Amazônia se dá para a pastagem. Com incentivos financeiros e investimentos em infraestrutura física, a pecuária extensiva na região de 
Itaituba pode vir a se transformar em uma atividade mais intensiva, como em algumas áreas do Estado do Mato Grosso, como a região de Sinop, Lucas do Rio Verde, Sorriso e São José do Xingu. Nessas áreas, observa-se a predominância de atividades relacionadas com o agronegócio, que se expressam na paisagem através de grandes talhões da agricultura anual e/ou de pastagem, ambas as atividades praticadas em um modelo intensivo, levando ao declínio da diversidade de usos da terra, supressão dos remanescentes florestais e ao rompimento com agricultura familiar ou de pequena escala (CAPARROZ, 2010; DOMINGUES; BERMANN, 2012; CRAICE; LOMBARDI, 2014, NAHUM; PAIXÃO JÚNIOR, 2014). Ao se seguir a dinâmica do modelo do agronegócio no Mato Grosso, a intensificação, ao invés de reduzir a área de produção e liberar outras áreas para diferentes usos, pode ameaçar a floresta primária e secundária, reduzindo as atividades extrativistas e a agricultura e pecuária familiar, produzindo uma paisagem menos diversificada. Entre as comunidades analisadas neste estudo, nenhuma está inserida diretamente na classe GIU alto e IDP baixo, mas pode-se observar a ocorrência de algumas comunidades próximas a essa classe, que provavelmente sofrem a influência dos processos que ocorrem nesse contexto.

\section{GIU alto e IDP alto}

Com a análise da figura 4, como observado nas leituras individualizadas do GIU e do IDP, a região do Planalto Santareno apresenta um alto índice de intensificação de uso da terra e, ao mesmo tempo, um alto índice de diversidade da paisagem, ainda que os processos dominantes sejam de concentração de terras em que os produtores de grãos recorrem à incorporação de grandes extensões de terra para a produção agrícola. Entretanto, como apontado anteriormente, Dal'Asta et al (2013) analisaram os padrões de ocupação com dados de desmatamento e de uso da terra e observaram que no período de 1990 a 2010, houve um aumento dos padrões associados a cultura de grãos e o surgimento de grandes fazendas de criação de gado, sobre áreas onde antes predominavam pequenos produtores rurais e as áreas de floresta. Mas, permaneceram ainda nessa região, cerca de118.385 hectares de áreas de vegetação secundária ( $53 \%$ em relação ao total da área desmatada no Planalto Santareno), seja pelo abandono das terras ou pela permanência de pequenos produtores rurais, cujo sistema de cultivo baseia-se na agricultura itinerante, no plantio da mandioca e na pecuária de pequena escala, produzindo uma paisagem que resiste e se apresenta ainda com algum nível de diversidade. D'Antona et al (2011) enfatizam, ainda, que a variação na estrutura de terras não se limitou ao aparecimento de estabelecimentos maiores, mas se deu também pela divisão dos lotes originais em estabelecimentos de menor tamanho, como já mencionado. Com isso, a presença de agricultura anual mecanizada, cuja cobertura ainda não domina a paisagem, entremeada por áreas de floresta, de agricultura de pequena escala, de remanescentes florestais e de pastagem, como pode ser observado na figura 5, confere uma heterogeneidade e um maior valor ao índice de diversidade de paisagem, quando comparada com as outras regiões analisadas. Assim, os altos valores do índice de diversidade de paisagem se dão pela coexistência de processos de intensificação e pela presença de atividades associadas aos pequenos produtores rurais, mais diversificadas. 

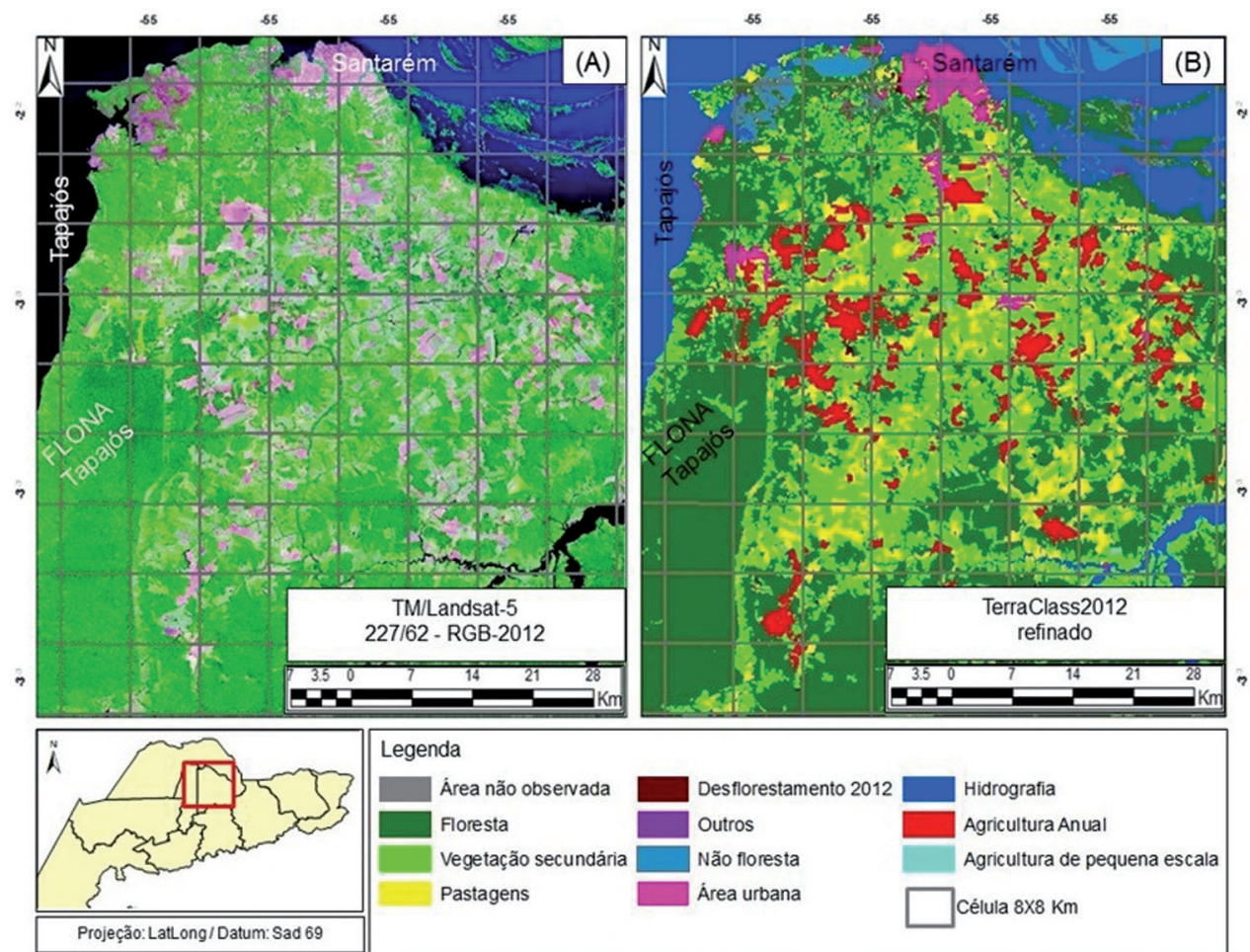

Figura 5 - Imagem do TM/Landsat-5 (A) e TerraClass2012-refinado (B) do Planalto Santareno

Fonte: Produção dos autores.

Como observado na figura 5, a agricultura anual ainda não domina a paisagem mas, com incentivos financeiros e investimentos em infraestrutura, o agronegócio vinculado a produção de grãos pode avançar, mudando a lógica de organização do território e de suas cadeias produtivas, até o rompimento com a agricultura familiar ou de pequena escala acarretando a, exclusão destas atividades agrícolas e das atividades extrativistas que ainda persistem na região, avançando em um modelo não inclusivo e que não incorpora na força das cadeias em construção as populações de pequenos produtores locais

A região ribeirinha do rio Tapajós, em Itaituba, também apresentou alto índice em ambos indicadores e também relacionado com atividades intensivas e extensivas do uso da terra que coexistem. Nesta mesma paisagem coexistem as grandes fazendas de pecuária e os pequenos produtores rurais dedicados a agricultura itinerante e a atividade pesqueira, devido à proximidade com o rio (DAL'ASTA et al,2014;). Embora a pecuária seja considerada como uma atividade com maior grau de intensificação que as demais atividades na métrica utilizada, esta atividade não é verdadeiramente intensiva, pois incorpora grandes extensões territoriais (SENA et al, 2013), com uma baixa lotação de cabeça de gado, reduzido uso de insumos e de técnicas de manejo para melhoria da pastagem, além do uso de mão de obra pouco qualificada. 
Nas áreas onde predominam o GIU alto e IDP alto, foram identificadas 6 (seis) comunidades, das 102 (cento e duas) amostradas neste trabalho, localizadas sobretudo na região do Planalto Santareno. Analisou-se os dados de produção agropecuária e de produtos extrativistas dessas comunidades. Neste contexto, a produção agropecuária é mais utilizada para geração de renda do que para subsistência, como pode ser observado na figura 6.A. Nesta figura observa-se que no máximo $33 \%$ das comunidades têm a produção agropecuária destinada ao consumo. Em contrapartida, a maior parte das comunidades vende a produção de roça e farinha ( $83 \%)$, seguida da carne e do leite (50\%) e em menor proporção, as frutas (33\%). Um dos componentes que estrutura essa lógica de comercialização da produção familiar se dá principalmente pela facilidade de acesso dos comunitários aos centros urbanos (sede dos municípios) como a feira do produtor rural em Santarém (SÁ et al, 2006). Esse acesso aos mercados é possível graças as estradas pavimentadas como a BR-163 (CuiabáSantarém), e outras rodovias estaduais (PA-443, PA445 e PA-431), bem como, em menor grau, pela proximidade com os portos instalados na região.

Com a disponibilidade de recursos florestais na região do Planalto Santareno, as comunidades podem desenvolver atividades extrativistas. Diante disso, observouse a partir da figura 6.B, que os produtos extrativistas são destinados mais ao consumo do que a venda. Mesmo que as comunidades estejam em uma região onde existe a pressão do agronegócio sobre a terra, em virtude da existência de áreas contínuas de remanentes florestais, que podem chegar até 1500 hectares, mesmo fora das Unidades de Conservação e, de alguns hábitos tradicionais preservados. Os comunitários ainda fazem uso de produtos medicinais e madeireiros $(83 \%)$, castanha do Pará $(67 \%)$, peixe $(50 \%)$ e, em menor proporção, de borracha $(17 \%)$. Com a adoção de um sistema de produção agropecuária voltada para a geração de renda, a venda dos produtos extrativistas é baixa, não atingindo mais do que $33 \%$ das comunidades (CAMILOTTI, 2016).
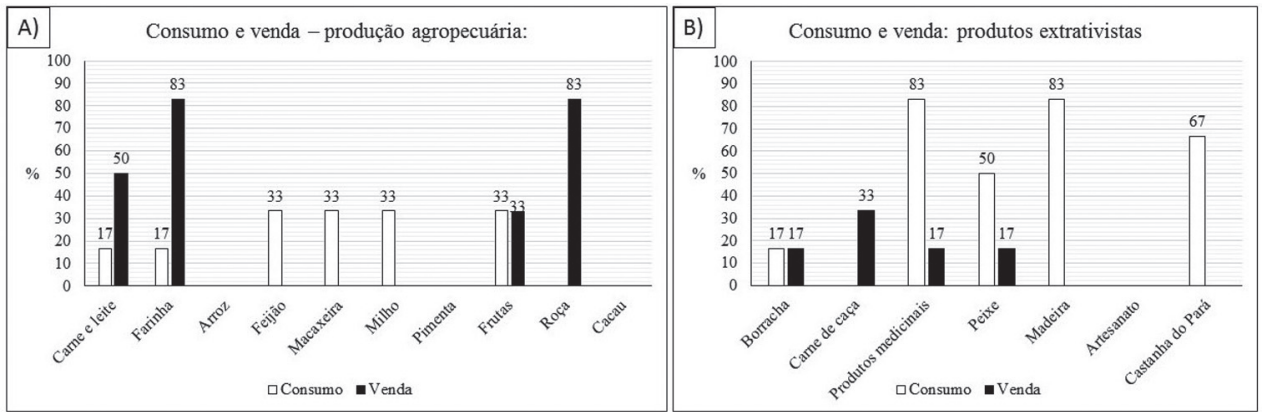

Figura 6 - Contexto: GIU alto e IDP alto: A) Consumo e venda - Produtos agropecuários; B) Consumo e venda- Produtos extrativistas

Fonte: Produção dos autores.

\section{GIU baixo e IDP alto}

O GIU baixo e IDP alto ocorre principalmente na região ribeirinha dos rios Tapajós e Arapiuns, na borda do Planalto Santareno e também na rodovia Transamazônica. Nessas áreas é comum o desenvolvimento da agricultura familiar produzida em pequenos lotes rurais. Neste contexto, a paisagem é caraterizada principalmente pelo rio, floresta, vegetação secundária, pastagem e agricultura familiar de pequena escala, com exceção da região da Transamazônica que está mais distante 
das áreas sob influência dos grandes rios. Nessa região, ocorrem atividades de roça e de pecuária no modelo extensivo. Esta última, demandando maior extensão de terras do que as áreas de roça.

A maior parte das comunidades amostradas neste estudo, estão inseridas na categoria, GIU baixo e IDP alto, totalizando 92 (noventa e duas) comunidades. Essas comunidades encontram-se em uma paisagem mais diversificada. As comunidades inseridas no contexto GIU baixo e IDP alto, ainda mantem a produção agropecuária diversificada que atende tanto ao consumo quanto a venda para geração de renda.

Na figura 7A, é apresentada a proporção de comunidades que consomem e vendem os produtos agropecuários. Neste contexto, observou-se que a farinha $(64 \%)$, as frutas $(61 \%)$, carne e o leite $(55 \%)$, macaxeira $(51 \%)$, milho $(49 \%)$, arroz $(37 \%)$ e feijão (36\%) são as principais produções destinadas ao consumo dentre as comunidades, as quais se constituem como elementos básico da dieta alimentar.

O excedente da produção agropecuária é vendido, sendo que a comercialização se concentra principalmente nos produtos oriundos da roça $(84 \%)$ e da produção de farinha $(75 \%)$, mas também são comercializados em menor proporção a carne e leite $(48 \%)$, frutas $(46 \%)$ e cacau $(27 \%)$ (Figura $7 \mathrm{~A})$.

Os produtos oriundos da roça como arroz, mandioca, macaxeira, milho, além da produção de farinha são amplamente consumidos tanto nas comunidades quanto são necessários para alimentar a população residente nos centros urbanos, por isso são os principais produtos produzidos pelas comunidades para a venda. Embora, a criação de gado seja uma das principais atividades de uso da terra na Amazônia (ARIMA E BARRETO, 2006), nas comunidades analisadas a criação é mais voltada para o consumo do que para a venda. Isso se deve, muitas vezes, a falta de recursos financeiros para manutenção adequada da pastagem e do próprio gado, consequência da falta de apoio, políticas públicas, associativismo, além da falta de assistência técnica (ROY, 2002). Neste caso, o comunitário que tenta inserir-se no mercado através de uma cadeia de valor econômico, se depara com pecuaristas mais capitalizados e que adotam sistemas mais intensivos, produzindo a custos mais baratos. Consequentemente, essa população menos capitalizada não consegue inserir-se no mercado, destinando a produção mais ao consumo do que a venda. Em relação ao cacau, a produção é baixa, quando comparada com as outras atividades, sendo essa produção mais importante para as comunidades da rodovia Transamazônica, onde ainda não se estabeleceu uma cadeia consolidada para o cacau.

No tocante ao extrativismo, tem-se uma diversidade de consumo, sendo a pesca $(90 \%)$, madeira $(87 \%)$ e os produtos medicinais $(80 \%)$ os produtos mais consumidos entre as comunidades, seguido da castanha do Pará $(51 \%)$, artesanato $(50 \%)$ e em menor proporção a carne de caça (18\%) e a borracha (10\%) (Figura 7B). Em suma, o padrão encontrado no consumo de produtos extrativistas mostra que as comunidades são fortes consumidoras e, ainda que não o utilizem para a geração de renda, indiretamente, o acesso a esses recursos é um fator que afeta a renda das comunidades. O artesanato é o produto o mais comercializado e atinge apenas $32 \%$ das comunidades, como observado na figura 7B. 

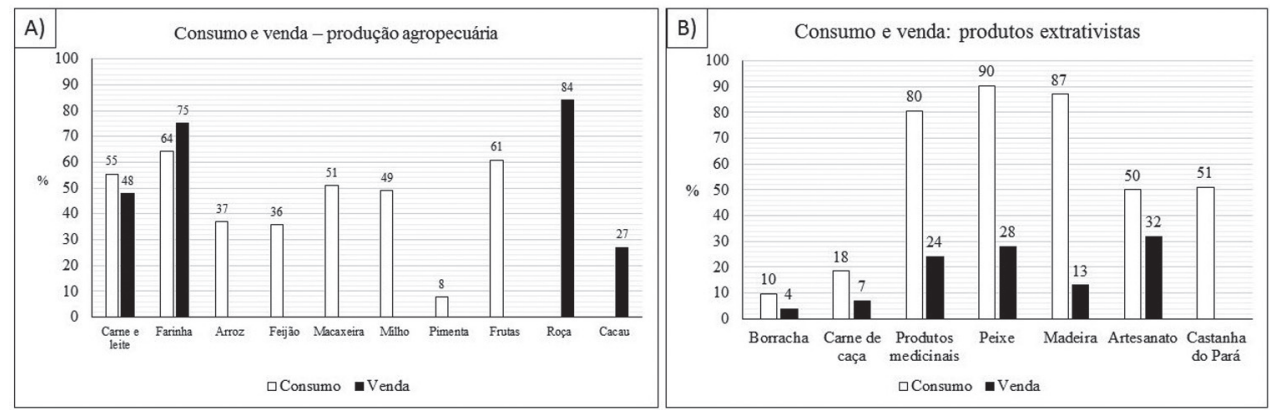

Figura 7 - Contexto: GIU baixo e IDP alto: A) Consumo e venda - Produção agropecuária; B) Consumo e venda- produtos extrativistas

Fonte: Produção dos autores.

\section{GIU baixo e IDP baixo}

Na região das Unidades de Conservação e áreas de remanescentes florestais, se concentraram valores de GIU baixo e IDP baixo. Essas áreas são constituídas principalmente por floresta e, em menor proporção, por vegetação secundária. Em virtude das restrições ambientais relacionadas com o uso da terra nas áreas de Unidades de Conservação, as famílias que desenvolvem agricultura podem cultivar em áreas de capoeira em até 1,25 hectares e, na floresta primaria, a área cultivada não pode ultrapassar 0,5 hectares (ESCADA et al, 2013). A criação de gado também é restrita nessas áreas podendo, cada família, criar no máximo 15 cabeças de gado dentro lote rural (AMARAL et al, 2009).

$\mathrm{Em}$ áreas onde predominam o GIU baixo e IDP baixo foram identificadas quatro comunidades, na região do Arapiuns. Neste contexto esperava-se que as comunidades com baixa intensificação do uso da terra e baixa diversidade da paisagem, tivesse uma produção agropecuária pouco expressiva. Porém, o dado de produção das comunidades apresentado na figura $8 \mathrm{~A}$ e $\mathrm{B}$, mostra que mesmo em proporções pequenas, as comunidades realizam atividades de produção agropecuária e extrativista. Embora a produção agropecuária para consumo seja pouco diversa, predominando as produções de farinha $(100 \%)$ e de frutas $(75 \%)$, existem comunidades que produzem arroz (50\%), milho (50\%), macaxeira (50\%), feijão (25\%), pimenta (25\%), carne e leite $(25 \%)$. A produção destinada à venda baseia-se principalmente na roça $(100 \%)$ e na produção de farinha (100\%) (Figura AB), atividades associadas, pois a roça é basicamente voltada para a produção de mandioca, principal matéria prima para produção de farinha. O extrativismo é mais diversificado que a produção agropecuária e seus produtos são utilizados para consumo, sendo os produtos medicinais, o peixe e a madeira, coletados por $100 \%$ de todas as comunidades e o artesanato por $75 \%$ delas (Figura $8 \mathrm{~B}$ ). Embora os produtos extrativistas destinados à venda não sejam comercializados por todas as comunidades, quase todos os recursos analisados neste trabalho são explorados por pelo menos metade delas (Figura 8B). Esta situação delimita potenciais para a estruturação de um APL com base em recursos extrativistas, uma vez que existe a tradição comunitária presente na realização da atividade e, em havendo mercados para estes produtos, a cadeia pode ser estruturada de modo inclusivo, criando possibilidades de geração de renda para os comunitários. Em síntese, a produção agropecuária e a produção extrativista, nas comunidades inseridas no contexto de baixa intensificação e baixa diversidade da paisagem, como seria de se esperar, é voltada mais ao consumo do que a venda. Essas comunidades 
contam com a presença de recursos naturais como o rio e os remanescentes florestais, que possibilitam o desenvolvimento de atividades extrativistas ao menos para a subsistência.
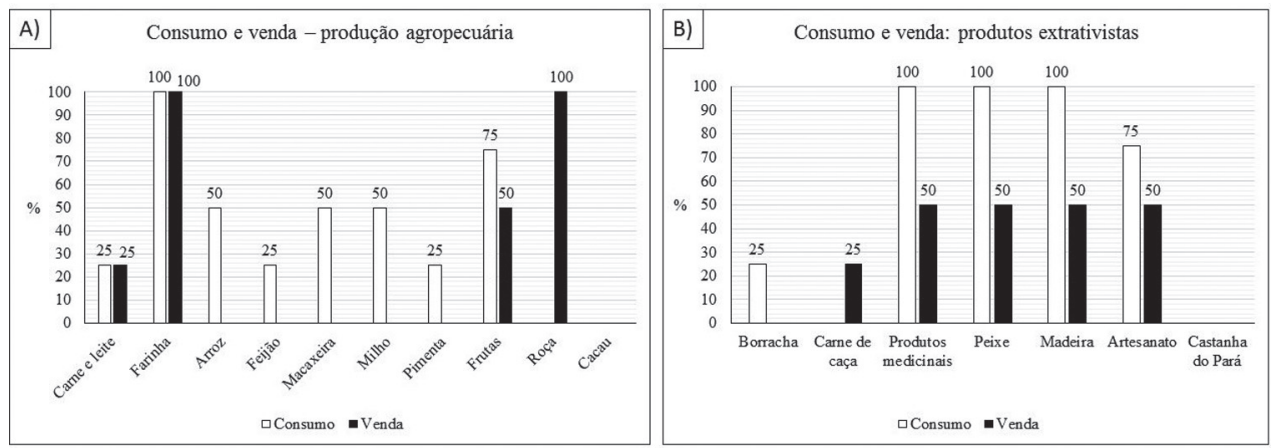

Figura 8 - Contexto: GIU baixo e IDP baixo: A) Consumo e venda Produção agropecuária; B) Consumo e venda- produtos extrativistas

Fonte: Produção dos autores.

\section{CONSIDERAÇÕES FINAIS}

Os indicadores propostos e implementados, na escala da paisagem, permitiram, caracterizar a estruturação espacial das paisagens das comunidades ribeirinhas e de terra firme, e demonstrando ser instrumentos eficazes para caracterizar os distintos padrões de uso e cobertura da terra associados às atividades com potencial de inserção em cadeias produtivas, que se manifestam no entorno das comunidades. Com isso, foi possível ampliar a compreensão do modo como estas comunidades se relacionam com as atividades produtivas agropecuárias e extrativistas, através da análise da paisagem na qual estão inseridas. A análise integrada das dimensões de intensificação e diversidade, nos permitiu observar que a intensificação do uso da terra nessa região está em processo. A paisagem não foi ainda inteiramente transformada pelo agronegócio, restando áreas para a pequena produção, além de remanescentes florestais e vegetação secundária que, por ora, são utilizadas em atividades de subsistência e extrativistas. Mas, o fato de existirem, apontam para a possibilidade de construção de arranjos produtivos inclusivos, pelo menos potencialmente, o que ofereceria alternativas para a população produtora extrativista local. Embora o agronegócio em Santarém esteja em uma temporalidade processual diferente do agronegócio estabelecido em Lucas de Rio Verde (CRAICE; LOMBARDI, 2014), com os novos investimentos em infraestrutura e incentivos do governo, essa situação pode mudar. Há o risco sério de marginalização e exclusão da população local nas cadeias produtivas do grão e da pecuária, ora em construção, o que levaria à redução dos recursos que têm por fonte as diferentes coberturas da terra, reduzindo as possibilidades de atividades para a subsistência das populações.

Com a metodologia apresentada neste trabalho, foi possível apresentar uma leitura territorializada das relações entre a estrutura da paisagem, as "pegadas" deixadas pelas formas de produzir, os agentes da produção, identificados na área de estudo durante trabalhos de campo e os processos presentes e em construção. Espera-se que este trabalho ajude a tornar visível, e territorializado, o mosaico de conflitos e de assimetrias, os potenciais e as limitações, para a disputa dos agentes de 
produção, e possa ser utilizado para subsidiar propostas que procuram pensar em estabelecer um modelo de desenvolvimento econômico para a região e suas comunidades, inclusivo, socialmente justo e ambientalmente responsável.

\title{
AGRADECIMENTO
}

\author{
Agradeço ao suporte financeiro do Projeto MSA-BNDES (Processo: \\ 1022114003005).
}

\section{REFERÊNCIAS}

ALVES, D. T. Ocupação indígena na foz do rio Tapajós (3260 - 960 AP): estudo do sítio Porto de Santarém, baixo Amazonas. Dissertação (mestrado em antropologia) Belém: Universidade Federal do Pará, 2012.

AMARAL FILHO, J. Sistemas e arranjos produtivos locais. Planejamento e políticas públicas. n. 36, 2011.

ARIMA, E. BARRETO, P. Pecuária e Madeira: Lucratividade, expansão e sustentabilidade. Ciência e Ambiente, Santa Maria, n. 32, 2006.

BECKER, B, K. A Amazônia nos Cenários para o Planejamento Ambiental. In: MMA. Os ecossistemas Brasileiros e os Principais Macrovetores de Desenvolvimento. Brasília: MMA, 1995.

BECKER, B. K.; MIRANDA, M.; MACHADO, L. O. Fronteira amazônica: questões sobre a gestão do território. Brasília: Editora UNB, 1990, 219p.

BOSERUP, E. Evolution agraire et pression demographique. Paris: Ed, Flammarion, 1970.

BRONDÍZIO, E. S. Intensficação agrícola, identidade econômica e invisibilidade entre pequenos produtores rurais amazônicos: Caboclos e colonos numa perspectiva comparada. In: ADAMS, C.; MURRIETA, R.; NEVES, W. (Org.), Sociedades Caboclas Amazônicas: Modernidade e Invisibilidade. São Paulo: Annablume, 2006.

BROWDER, J.O.; GODFREY, B. Rainforest Cities: Urbanization, Development and Globalization of the Brazilian Amazon. New York: Columbia University Press, 1997.

CAMILOTTI, V. L. Recursos florestais extrativistas em comunidades no sudoeste do Pará: Uso, importância e características da paisagem, 2016, 180p, Tese (Doutorado), Centro de Ciência do Sistema Terrestre, Instituto Nacional de Pesquisas Espaciais, São José dos Campos, 2016.

CAPARROZ, B.M. Ambiente, urbanização e agroindústria: a especificidade de Lucas do Rio Verde - MT, In: ENCONTRO NACIONAL DE ESTUDOS POPULACIONAIS, 17, 2010, Caxambu, Anais....Caxambu, 2014.

CARDoso, A. C. D; MONTEIRO, A. M. V. Qual a Natureza do Urbano na Amazônia Contemporânea? O Urbano Extensivo e os Circuitos da Economia: O Papel das Redes na Construção dos Lugares e na Configuração Multi-escala do Urbano Amazônico. UsbisAmazônia, 2014. Disponível em: http://www.dpi.inpe.br/urbisAmazonia/lib/exe/ fetch.php?media=urbis: producoes: projeto_urbis_relatorioparcial_ano_3_completo.pdf. Acesso em: 17 jun 2016.

CANUTO, A. Agronegócio: a modernização conservadora que gera exclusão pela produtividade. Revista NERA, Ano 7, p. 1-12, 2004. 
CORTES, J. C.; D'ANTONA, A, de O. Reconfiguração do meio rural no oeste do Pará: Uma abordagem multiescalar da mobilidade e distribuição da população, e da mudança no uso-cobertura da terra. In: ENCONTRO NACIONAL DA ANPPAS, 5, Florianópolis, Anais... Florianópolis, v.1, p. 1-21, 2010, Disponível em: http://www.anppas.org.br/ encontro5/cd/artigos/GT14-376-907-20100903222640.pdf.Acesso em: 15 jan 2015.

COSTA, F. A. Trajetórias Tecnológicas como Objeto de Política de Conhecimento para a Amazônia: Uma metodologia de delineamento. Revista Brasileira de Inovação, v. 8, n. 1, p. 35-86, 2009.

COSTA, F. A. Arranjos produtivos locais no estado do Pará: mapeamento, metodologia de identificação e critérios de seleção para políticas de apoio. In. BNDES Projeto. Análise do Mapeamento e das Políticas para Arranjos Produtivos Locais no Norte, Nordeste e Mato Grosso e dos Impactos dos Grandes Projetos Federais no Nordeste. Brasília: BNDES, 2010.

COSTA, F. A; INHETVIN, T. A Agropecuária na Economia de Várzea da Amazônia: Os desafios do desenvolvimento sustentável. 1. ed. Manaus: Ibama/ProVárzea, 2006.

COSTA, F. A. Formação rural extrativismo na Amazônia: Os desafios do desenvolvimento capitalista (1720-1970), Belém: NAEA, 2012a.

COY, M. Rondônia: Frente pioneira e programa POLONOROESTE: O processo de diferenciação sócio-econômica na perifieria e os limites do planejamento público, Tubinguen Geographhische Studien, n. 95, p. 253-270, 1987.

CRAICE, C.; LOMBARDI, T.T. Mobilidade e fronteira em duas áreas da fronteira amazônica - Lucas do Rio Verde (MT) e Santarém (PA). In: ENCONTRO NACIONAL DE ESTUDOS POPULACIONAIS, 19, 2014, São Pedro, Anais... São Pedro,2014.

DAL'ASTA, A.; ESCADA, I, S.; AMARAL, S.; MONTEIRO, A. M, V. Evolução do arranjo espacial urbano e das terras agrícolas no entorno de Santarém (Pará) no período de 1990 a 2010: Uma análise integrada baseada em sensoriamento remoto e espaços celulares. In. SIMPÓSIO BRASILEIRO DE SENSORIAMENTO REMOTO - SBSR, 16, FOZ do Iguaçu, Anais... São José dos Campos: INPE, p.6381-6388, 2015. Disponível em: <http://www.dsr.inpe.br/sbsr2013/files/p0419.pdf>. Acesso: 16 jun 2016.

DAL'ASTA, A. P. SOUZA, A. R; PINHO, C. M.D.; SOARES, F. R.; REGO, G. F. J.; SIQUEIRA, J. M.; ESCADA, M. I. S.; BRIGATTI, N. ;AMARAL, S.; CAMILOTTI, V. L.; DÓRIO, V.E. E. M.Estrutura, serviços e a conectividade das comunidades de terra firme do sudoeste do PA. São José dos Campos: INPE, 2014.

D'ANTONA, A.; VANWEY, L.; LUDEWIGS, T.Polarização da estrutura fundiária e mudanças no uso e na cobertura da terra na Amazônia. Acta, Amazônica, v.41, p. 223-232, 2011.Disponível em: http://www.scielo.br/pdf/aa/v41n2/v41n2a06. Acesso em: 29 jan de 2016.

DOMINGUES, M. S; BERMANN, C. O arco de desflorestamento na Amazônia: Da pecuária a soja. Ambiente e Sociedade. São Paulo, v. 15, n. 2, 2012.

EMBRAPA; INPE. TerraClass: Levantamento de informações de uso e cobertura da terra na Amazônia- Sumário Executivo. São José dos Campos: INPE, 2008. Disponível em: http://www.inpe.br/cra/projetos_pesquisas/sumario_executivo_terraclass_ 2008.pdf. Acesso em: 21 jan, 2014.

TerraClass:2012. São José dos Campos: INPE, 2014. Disponível em: http:/ /www.inpe.br/cra/projetos_pesquisas/terraclass2012.php. Acesso em: $10 \mathrm{fev}, 2015$.

ESCADA, M. I. S.; DAL'ASTA, A.P ; SOARES, F. R.; ANDRADE, P. R.; PINHO, C. M. D.; MEDEIROS, L. C. C. CAMILOTTI, V. L.; SANTOS, J. N. A; FERREIRA, V. C.; AMARAL, S. Infraestrutura, serviço e conectividades ribeirinhas do Arapiuns. São José dos campos: INPE, 2013. 
FEARNSIDE, P,M, O avanço da soja como ameaça à biodiversidade na Amazônia. In: WATANABE, S. (Ed.), SIMPÓSIO DE ECOSSISTEMAS BRASILEIROS: CONSERVAÇÃO, 5, Anais... v. I: Conservação e Duna. Universidade Federal de Espírito Santo ES.Vitória, 2000.

FRANCA, C. Dinâmicas globais e arranjos produtivos para agricultura familiar: o caso do polo de fruticultura Juazeiro-Petrolina no território do Vale do Submédio do Rio São Francisco, Região Nordeste do Brasil. REVUES, 2012. Disponível em: http:// configuracoes.revues.org. Acesso em: 22 abril 2016.

HOMMA, A. K. O. Ciência e tecnologia para o desenvolvimento. In: CONGRESSO BRASILEIRO DE FITOPATOLOGIA, 45, Anais... Manaus, 2012.

IBGE. Produção Agrícola Municipal 2014. Rio de Janeiro: IBGE, 2015a.

Produção da Pecuária Municipal 2014.Rio de Janeiro: IBGE, 2015b.

Censo Demográfico 2010.

INSTITUTO NACIONAL DE PESQUISAS ESPACIAIS (INPE), FotoTeca. São José dos Campos, 2015, Catálogo. Disponível: http://www.obt.inpe.br/fototeca/fototeca.html. Acesso em: 14 jan, 2014.

TerraPixel. CASTEJON, E. São José dos Campos: INPE, 2011. Disponível em: http://www.dpi.inpe.br/ castejon/wiki/doku.php?id=wiki:terrapixel. Acesso em: 16 ago 2015.

MATOS, M. G. P; BORIN, E. ; CASSIOLATO, J. E . Uma década de evolução dos Arranjos Produtivos Locais. 1. ed. Rio de Janeiro: Epapers, 2015.

MERTENS, B. ; LAMBIM, E. F. Spatial modeling of deforestation in southern Cameroon, spatial disaggregation of diverse deforestation process, Applied Geography. v. 17, n. 2, p. 143-162, 1997.

MCGARIGAL, K. Fragstats Help. Amherst: University of Massachusetts, 1996.

MCGARIGAL, K.; MARKS, B. J. FRAGSTATS: spatial pattern analysis program for quantifying landscape structure. Gen, Tech, Report PNW-GTR-351.USDA Forest Service, Pacific Northwest Research Station, Portland, 1995.

METZGER, J. P. O que é ecologia de paisagem?, Revista Biota Neotropica, Campinas, V. 1, n. 1/2, 2001.

NAHUM, J. S.; PAIXÃO JÚNIOR, P. R. C. Encontros e desencontros: fronteira, agronegócio da soja e campesinato no Planalto Santareno (PA ). Presidente Prudente: Revista NERA, v. 17, n. 25, p. 47-70, 2014.

OLIVEIRA, C.; SANTANA, A.; HOMMA, A. Os custos de produção e a rentabilidade da soja nos municípios de Santarém e Belterra, estado do Pará. Acta Amazonica, v. 43, p. 23-31, 2013.

OLIVEIRA, C. M; SANTANA, A. C. A Governança no Arranjo Produtivo de Grãos de Santarém e Belterra, Estado do Pará: uma análise a partir do grão soja. RESR, Piracicaba-SP, v. 50, n. 4, p. 683-704, 2012.

PEDLOWSKI, M. A ; DALE, V. H. Land use practices in Ouro Preto d'Oeste, Rondônia, Brazil.Tennessee: Oak Ridge National Laboratory, 1992, 12 p, (ORNL Technical Manuscript 3850).

PEREIRA, S. A.; FABRÉ, N. N. Uso e gestão do território em áreas de livre acesso no Amazonas, Brasil. Acta Amazônica, v. 39, n. 3, p. 561-572, 2009. 
RapidEye. RapidEye Mosaics Product Specifications. Blackbridge, 2014. Disponível em: http://blackbridge.com/rapideye/mosaics/index.html. Acesso em: 15 dez.2014.

RAMOS, R. M. Caça de subsistência e conservação na Amazônia (Reserva Extrativista Rio Xingu, Terra do Meio, Pará): Ecologia da caça e avaliação de impactos na fauna. Tese (Doutorado em Ecologia) - UNB, Brasília, 2013.

RIVERO, S.; ALMEIDA, O.; ÁVILA, S.; OliVeirA, W. Pecuária e desmatamento: Uma análise das principais causas diretas do desmatamento na Amazônia. Nova Economia, Belo Horizonte, v. 19, n. 1, 2009.

ROY, G. C; VEIGA, I (Org).Agricultura Familar: Pesquisa, formação e desenvolvimento. Belém: UFPA/CA/NEAF,2002.

SAATY, T. L. The Analytic Hierarchy Process. New York: McGraw-Hill, 1980.

SÁ, M. E. R; COSTA, S. M. G; TAVARES. L, P. O. O rural-urbano em Santarém: interfaces e territórios produtivos. In: CARDOSO, A. C. D. (Org.). O rural e o urbano na Amazônia: diferentes olhares em perspectivas, Belém: EDUFPA, 2006.

SANTOS, R. J. S. Seleção de indicadores da qualidade do transporte público urbano de passageiros por ônibus. Instituto Militar de Engenharia - IME. Dissertação (mestrado em Engenharia de Transportes). IME, 2004.

SENA, A. L. S; SANTOS, J. C.; SANTOS, M. A. S. Caracterização da agroindústria do leite na região oeste do estado do PARÁ. Amazônia: Ci.e Desenvolvimento. Belém, v. 8, p. 63-78, 2012.

SOUZA, A. R. Economia e natureza: Padrões de uso e cobertura da terra associados a atividades agropecuárias e extrativistas de comunidades do sudoeste do Pará. Dissertação (Mestrado em Sensoriamento Remoto) - Instituto Nacional de Pesquisas Espaciais (INPE), São José dos Campos, 2016. Disponível em: http://urlib.net/ 8JMKD3MGP3W34P/3M8SD78.

SOUZA, A. R.; ESCADA, M. I. S.; MONTEIRO, A. M. V. Gradientes de intensificação do uso da terra: Análise no entorno de comunidades ribeirinhas e de terra firme em Santarém e Belterra (PA) entre 1990 e 2010. In: SIMPÓSIO BRASILEIRO DE SENSORIAMENTO REMOTO. SBSR, 17. João Pessoa-PB. Anais... São José dos Campos: INPE, p.6381-6388, 2015, Disponível em: <http://www.dsr.inpe.br/sbsr2015/files/ p1256.pdf>, Acesso: 16 jun 2015.

TerraView 4.2.2. São José dos Campos, SP: INPE, 2010. Disponível em: www.dpi.inpe.br/terraview. Acesso em: 16 dez 2014.

WALKER, R.; DEFRIES, R.; VERA-DIAZ, M. D. C.; A Expansão da Agricultura Intensiva e Pecuária na Amazônia Brasileira, Revista Amazonia and Global Change. P. 61$81,2013$.

Recebido em agosto de 2016 Revisado em março de 2017 Aceito em abril de 2017 